\title{
Heterogeneous Beliefs, Public Information, and Option Markets
}

\author{
Zhenjiang Qin
}

\section{CREATES Research Paper 2012-23}




\title{
Heterogeneous Beliefs, Public Information, and Option Markets*
}

\author{
ZHENJIANG QIN ${ }^{\dagger}$ \\ Department of Economics and Business and CREATES \\ Aarhus University, Denmark
}

15 April 2012

\begin{abstract}
In an incomplete market setting with heterogeneous prior beliefs, I show that public information and strike price of option have substantial influence on asset pricing in option markets, by investigating an absolute option pricing model with negative exponential utility investors and normally distributed dividend. I demonstrate that heterogeneous prior variances give rise to the economic value of option markets. Investors speculate in option market and public information improves allocational efficiency of markets only when there is heterogeneity in prior variance. Heterogeneity in mean is neither a necessary nor sufficient condition for generating speculations in option markets. With heterogeneous beliefs, options are non-redundant assets which can facilitate side-betting and enable investors to take advantage of the disagreements and the differences in confidence. This fact leads to a higher growth rate in the investors' certainty equivalents and, thus, a higher equilibrium interest rate. The public information system facilitates improved dynamic trading opportunities in option markets based on the heterogeneously updated posterior beliefs. With an intermediate signal precision and the option with intermediate strike price, the highest efficiency of sidebetting is achieved, reflected by a unique maximum point of the ex ante equilibrium interest rate. The public signal precision affects ex ante equilibrium risk premium only via its relationship with option.
\end{abstract}

${ }^{*}$ Financial support from the Center for Research in the Econometric Analysis of Time Series (CREATES) funded by the Danish National Research Foundation is gratefully acknowledged.

${ }^{\dagger}$ Address correspondence: Department of Economics and Business, Building 1322, Bartholins Allé 10, Aarhus University, DK-8000 Aarhus C, Denmark; zqin@econ.au.dk, +45 87165287. 
Keywords: Heterogeneous Beliefs; Public Information Quality; Option Market; Dynamic Trading; Bayesian Learning

JEL classification: G1, G11, G12 


\section{Introduction}

Black and Scholes (1973) develop a relative option pricing model by introducing the concept that the value of an option can be replicated by trading underlying asset continuously, hence in their setting, the option is a redundant asset. However, in the real world, hedgers, speculators, and arbitrageurs trade actively in all the main option exchanges ${ }^{1}$. This fact signals options are far from redundant, and are capable of facilitating market efficiency. Otherwise, investors are indifferent in holding them, and option markets vanish due to non-negligible maintenance costs. Although several factors such as stochastic volatility, jumps, trading frictions (e.g. transaction costs, and capital constraints), and heterogeneous information, are found to be responsible for the non-redundancy of options ${ }^{2}$, apparently this problem is not yet addressed to a completely satisfying extent. On the other hand, public information or signal such as earnings and dividend announcements, mergers and acquisitions, macroeconomic announcements, accounting reports are long recognized to have substantial impacts on the financial markets ${ }^{3}$. However, few studies shed light on the relationship between options and public information quality. Thus, questions arise: Under what condition does the public information quality exert influence on option market? How does public information quality affect the non-redundancy of option markets? Does public signal precision interact with option to play important roles in forming an allocational efficient market? As an attempt to answer those questions, this paper provides information-based models with heterogeneous beliefs which yield explanations for non-redundancy of options, and address the role of public signal precision in the option markets.

I develop a two-period absolute option pricing model in an incomplete market setting with many negative exponential utility investors holding heterogeneous prior beliefs, and where the dividend is normally distributed. I achieve mainly two findings. First, heterogeneous prior variances provide economic value to the option markets in the sense that the investors speculate in the option market, which indicates the option is non-redundant, and imperfect public signal improves the allocational efficiency of option markets only when there is heterogeneity in prior precision. Second, even though the strike price of option affects the ex ante risk premium on the risky underlying asset regardless of the presence of the public

\footnotetext{
${ }^{1}$ For empirical evidence, see, e.g., Easley, O'Hara, and Srinivas (1998), Cherian and Weng (1999), Vanden (2004), and Chakravarty, Gulen, and Mayhew (2004).

${ }^{2}$ Related works include Hull and White (1987), Heston (1993), Liu and Pan (2003), and Brennan and Cao (1996) among many others. Note Brennan and Cao (1996) use a quadratic derivative to achieve Pareto efficient consumption allocations, but their model requires new exogenous supply shocks to the stock to generate trading volume.

${ }^{3}$ Recent empirical evidence suggests that macroeconomic announcements and employment figures have pronounced impact on financial markets. Literatures include, e.g., Feltham and Pae (2000), Andersen, Bollerslev, Diebold, and Vega (2003), and Richardson, Sloan, Soliman, and Tuna (2005).
} 
signal, the public signal precision (the invert of variance of noise) affects the ex ante risk premium only via its relationship with the option.

The model is a derivative oriented and two-period extension of the classic single-period capital asset pricing model (CAPM) with heterogeneous beliefs of Lintner (1969). Specifically, the investors hold different prior beliefs at $t=0$ on the normally distributed $t=2$ dividend, i.e., the prior beliefs of mean and precision (the inverse of variance) differ. These assumptions imply that the investors agree to disagree due to, for instance, difference in their experiences or DNA. The investors update their beliefs according to the Bayes' rule with a public signal received at $t=1$ from a simple public information system. ${ }^{4}$ The public signal is equal to the $t=2$ dividend on the risky underlying asset plus independent noise. Moreover, the investors have concordant beliefs (Milgrom and Stokey 1982) or homogeneous information beliefs (Hakansson, Kunkel, and Ohlson 1982) on the normally distributed noise in the signal, i.e., a zero mean and a common signal precision. These assumptions allow to measure the informativeness of public information system by the public signal precision. Furthermore, the investors can trade and speculate in the option markets, the underlying asset markets and the zero-coupon bond markets at $t=0$ and $t=1$, and consume at $t=0$ and $t=2$. Solving for equilibriums in an exchange economy, I investigate the impact of the heterogeneity in beliefs, the strike price, and the public information quality on option pricing and the other asset pricing properties in option markets.

Heterogeneity in the prior variance creates the opportunities for speculation in option markets. With homogeneous prior variance, the investors do not trade in the option markets. The intuition is related to the results in Wilson (1968): Pareto efficient allocations in settings with heterogeneous beliefs require not only an efficient sharing of the risks, but also an efficient side-betting arrangement. With homogeneous prior variance, the Pareto efficient side-betting based on their disagreements about the mean can be achieved by trading only in the risky underlying asset and the zero-coupon bond at $t=0$. The CAPM-like equilibrium price under heterogeneous beliefs is obtained. However, when the investors have different prior precision, trading only in the underlying asset and the zero-coupon bond at $t=0$ does not facilitate efficient side-betting. The investors tend to speculate in the option markets. Take a European call option market for example, the investor with a low (high) prior precision takes long (short) position in the call option with convex payoff to achieve a terminal payoff which is a convex (concave) function of the dividend. This speculative strategy is the so-

\footnotetext{
${ }^{4}$ Note this paper considers the economy-wide impacts of public information and, thus, the public information should be interpreted as, for instance, macroeconomic reports of aggregate consumption. And an information system is a set of potential signals that present conditional (or signal dependent) probabilities that each state at the terminal date occurs.
} 
called Gamma trading strategy ${ }^{5}$.

Speculations in option markets increase the allocational efficiency of the equilibrium. This result can be detected from the change of asset pricing properties when investors' speculative behaviors change. First, conditional on identical average prior precision, the higher heterogeneity in beliefs, the more opportunities in speculations, and the more advantage of the disagreements and the differences in confidence among the investors can be taken. This effect leads to a higher efficiency of side-betting and more gains in trading options. The trading gains translate into increased certainty equivalents of the terminal consumption, and result in a higher equilibrium consumption growth, and thus a higher equilibrium interest rate. Second, investors tend to trade in options with an intermediate strike price. Since this type of options carry the most substantial convexity in their payoff, and thus the investors can effectively and actively speculate in the option markets. Third, the imperfect public signal facilitates speculations. When the investors have heterogeneous prior dividend precision, they update their posterior beliefs differently with imperfect public signal, and this gives the basis for additional trading gains contingent on the imperfect public signal. Another round of trading using Gamma trading strategies at $t=1$ partly facilitates the efficient side-betting. Eventually, a combination of the option with intermediate strike price and public information system of the intermediate signal precision enables the investors to achieve the highest efficiency of side-betting, reflected by the unique maximum point of the ex ante equilibrium interest rate.

Public signal precision affects the ex ante equilibrium risk premium on the risky underlying asset via options. The underlying mechanism is that the convexity of the option payoff varies with the public signal precision, through this relationship, the speculative positions in the underlying asset and the option are affected by the public signal precision. This fact gives rise to a signal-precision-dependent covariance between the marginal utility of consumption and the dividend and, thus, a signal-precision-dependent ex ante equilibrium risk premium. With an intermediate strike price, the impact of the public signal precision on the ex ante equilibrium risk premium is nontrivial (see Figure 9). Compare to the benchmark model in Christensen and Qin (2012), in which the ex ante risk premium is independent of the public signal precision, the ex ante risk premium in this paper is not aligned with investor welfare (as a function of the signal precision). The equilibrium interest rate and the investor welfare, however, are still perfectly aligned. This fact has an implication that it may be wise to be cautious in making policy statements about, for example, financial reporting regulation, based on empirical measures of equity premia (which are hard to measure reliably anyway).

\footnotetext{
${ }^{5}$ See more about Gamma trading strategies in e.g., Hull 2009, Chapter 17.
} 


\section{Review of the Literature}

Some studies on the impact of information system and heterogeneity in beliefs on asset pricing are closely related to this work ${ }^{6}$. Li (2008) assumes that investors believe the growth rate of the dividend to be a constant and known perfectly. This assumption enables closedform solutions for vanilla European option prices and closed-form approximations for barrier options. His model offers a rationale for observed implied volatility patterns in an equilibrium setting and is also easy to implement in practice. However, in his model, the role of the option to facilitate side-betting is not explored, and his model is silent with respect to the influence of information system. Those issues are investigated in this paper.

In a similar effort, Buraschi and Jiltsov (2006) employ a model, based on the work by Detemple and Murthy (1994), to investigate the option markets with heterogeneous beliefs. They show that the heterogeneity in beliefs has significant pricing implications by plotting equilibrium asset pricing properties such as stock price and stock volatility as functions of the difference in beliefs. Their results indicate that the heterogeneous beliefs are strongly related to optimal portfolio holdings, stock volatility, equity premium, stock prices, option prices and skewness in equity returns.

My model differs with Buraschi and Jiltsov (2006) in several aspects. First, the investors' utility functions and the dividend structure are different. Second, Cuoco and He (1994) demonstrate the equilibrium with a stochastic weight in the representative agent utility is in general not Pareto efficient. Hence markets in Buraschi and Jiltsov (2006) are essentially incomplete, and they do not illustrate how much the option can help to improve the efficiency of side-betting. This paper demonstrates to what degree the option can enhance the market allocational efficiency. Third, the approach to study the impacts of heterogeneity in beliefs is different. They plot the asset pricing properties as functions of the difference in the updated beliefs scaled by the signal volatility, hence their heterogeneous beliefs carry the effect of the information system. In fact, they do not study the impact of the information quality. However, I plot the asset pricing properties as functions of the different priors, thus the analysis in this paper probes the impact of the heterogeneity in beliefs and the public information quality separately.

Also note that Buraschi and Jiltsov (2006) and David (2008) solve for the equilibrium by constructing a representative agent utility through taking weight of the two different individual utilities, and the weight is stochastic and endogenized in the equilibrium as a

\footnotetext{
${ }^{6}$ Recent contributions of asset pricing in economies with incomplete information include, e.g., David (1997), Brennan (1998), Veronesi (1999, 2000), and Brennan and Xia (2001). Efforts to establish the socalled differences-of-opinion models in financial markets include, e.g., Cao and Ou-Yang (2009), and Banerjee and Kremer (2010). These literature assume the investors have homogeneous beliefs about the fundamentals in the economy, but disagree on how to interpret common public signals.
} 
function of the difference in beliefs. Hence the change of heterogeneity in beliefs results in the change of the value of the weight. However, when plotting the asset pricing properties as functions of the heterogeneity in beliefs, they fix the value of the weight at a certain level. Hence, their approach to analyze the impacts of the heterogeneous beliefs can be considered to be conditional. Models of unconditional analyses are provided in this paper.

Christensen and Qin (2012) study a benchmark model in which the investors speculate in a risky asset and a zero-coupon bond. They show that the public information system is able to facilitate side-betting and enable the investors to take advantage of the disagreements in the prior variance. A more efficient market gives rise to a higher equilibrium interest rate.

Based on the idea of Wilson (1968), Christensen and Qin (2012) introduce a dividend derivative which pays off the square of dividend in the terminal date to facilitate sidebetting and achieve a Pareto efficient equilibrium. This extreme case gets rid of the need for dynamic trading based on the public signals. Note that the dividend derivative in their model resembles a "smooth" straddle. This idea gives a motivation to employ a true straddle, i.e., long positions in both a call and a put option with the same strike price, as a replacement of the dividend derivative and explore the ability of the options in facilitating side-betting. The straddle may not be able to effectively complete the market. However, the investors still can employ the Gamma strategy by trading straddles to achieve a more satisfactory convexity of their payoff. This paper investigates this intermediate case to address issues such as the role of options to help establish allocational efficient markets and the role of the public information system in the option markets.

This paper is organized as follows. The primitives of the economy and the learning mechanism are established in Section 2. Section 3 establishes a single-period model in which investors receive no signal or perfect signal, and investigate the effects of the heterogeneous beliefs and the strike price on asset pricing properties such as the equilibrium interest rate and the equilibrium risk premium with numerical examples. Section 4 investigates the equilibrium with imperfect public signal and discusses the effects of the public signal precision on asset pricing properties. Section 5 concludes the paper and discusses possible extensions. Proofs and algorithms to solve for the equilibriums are presented in Appendix A. Appendix B provides the derivations of models when investors speculate with straddles.

\section{The Model}

I examine the impacts of the heterogeneity in priors, the strike price and the public signal precision on option pricing properties in an exchange economy in which many types of agents have identical preferences but differ in their prior beliefs about the distribution of forthcoming 
dividend.

\subsection{The Investors' Beliefs and Preferences}

There are two consumption dates, $t=0$ and $t=2$, and there are $I$ investors who are endowed at $t=0$ with a portfolio of underlying asset, potentially receive public information at $t=1$, and receive terminal normally-distributed dividends from their portfolio of underlying asset at $t=2$. There are three marketed securities: a zero-coupon bond which pays one unit of consumption at $t=2$ and is in zero net supply, the shares of a single risky firm which have net supplies $Z$ at $t=0$ and $t=1$, and a European call option with a strike price at $K$ which has zero net supplies at $t=0$ and $t=1$, and the underlying asset is the share of the firm. The net supplies are fixed: the $I$ investors are endowed with firm shares $\bar{z}_{i} ; i=1,2, \cdots, I$. In addition, the investors have endowments $\bar{\theta}_{i}$ units of the European call option in zero net supply at $t=0$, and the investors are endowed with $\bar{\gamma}_{i}$ units of $t=2$ zero-coupon bond in zero net supply also. The trading of the marketed securities takes place at $t=0$ and $t=1$, based on heterogeneous prior beliefs. Let $\theta_{i t}, x_{i t}$ and $\gamma_{i t}$ present the investor $i$ 's portfolio of the option, the share and the units had of the zero-coupon bond after trading date $t$, respectively. Hence, the market clearing conditions at date $t$ are

$$
\sum_{i=1}^{I} \theta_{i t}=0, \quad \sum_{i=1}^{I} \gamma_{i t}=0, \quad \sum_{i=1}^{I} x_{i t}=Z \equiv \sum_{i=1}^{I} \bar{z}_{i}, t=0,1
$$

The dividend paid by the firm's shares at date $t=0$ is denoted $d_{0}$, and at date $t=2$ is denoted $d$. The investors have heterogeneous prior beliefs on the distribution of the dividend, and the individual perceived distribution is represented by $N\left(m_{i}, \sigma_{i}^{2}\right)$, where $m_{i}$ is the expected dividend per share and $\sigma_{i}^{2}$ is the variance of firm dividends per share for the investor $i$. Note that since the investors have common and not asymmetric information, they are aware of each others' different inferences, arising from their different priors. Under this heterogeneous beliefs formulation, the investors agree to disagree. Morris (1995) proposes a method to endogenize the difference in beliefs and formulations. He shows that it is fully consistent with rationality to have heterogeneous priors.

The investor $i$ has a public information system $\eta$ reporting public signal $y$ at $t=1$, which has impacts on asset prices. The investors can trade in the riskless asset in zero net supply with price $\beta_{0}$ at $t=0$ and price $\beta_{1}$ at $t=1$. The underlying asset price and the call option price at $t=0$ are denoted $p_{0}(\eta)$ and $\pi_{0}(\eta)$, respectively. The underlying asset price and call option price at $t=1$ given the public signals $y$ are represented by $p_{1}(y)$ and $\pi_{1}(y)$, respectively, which reflect the fact that the ex post asset prices may be affected by the public 
signals available to the investors at $t=1$.

The investor $i$ 's consumption at date $t$ is denoted $c_{i t}$ and they have time-additive utility. The common period-specific utility is negative exponential utility with respect to consumption, i.e., $u_{i 0}\left(c_{i 0}\right)=-\exp \left[-r c_{i 0}\right]$ and $u_{i 2}\left(c_{i 2}\right)=-\exp [-\delta] \exp \left[-r c_{i 2}\right]$, where $r>0$ is the investors' common constant absolute risk aversion parameter. Moreover, the investors have common utility discount rate, $\delta$, for date $t=2$ consumption.

\subsection{Learning Mechanism}

Bayesian learning provides a core concept of information processing in financial markets. I assume that the investors update their beliefs in a Bayesian fashion.

Specifically, the public signal $y$ is generated by $y=d+\varepsilon, \varepsilon \sim N\left(0, \sigma_{\varepsilon}^{2}\right)$, where $h_{\varepsilon} \equiv 1 / \sigma_{\varepsilon}^{2}$ is the signal precision which is common knowledge of all the investors. In other words, the investors have concordant beliefs (Milgrom and Stokey 1982) or homogeneous information beliefs (Hakansson, Kunkel, and Ohlson 1982). I use $h_{(\cdot)} \equiv 1 / \sigma_{(\cdot)}^{2}$ throughout to denote the precisions for the associated variances. When $h_{\varepsilon} \rightarrow \infty$, the public signal is the realization of the dividend. Moreover, the terminal dividend $d$ and the noise $\varepsilon$ are independent and jointly normally distributed. Thus, the joint distribution of the public signal and dividend from the perspective of investor $i$ is $\varphi_{i}(y, d) \sim N\left(\mu_{i}, \Sigma_{i}\right)$, where

$$
\mu_{i}=\left(\begin{array}{c}
m_{i} \\
m_{i}
\end{array}\right), \Sigma_{i}=\left(\begin{array}{cc}
\sigma_{i}^{2}+\sigma_{\varepsilon}^{2} & \sigma_{i}^{2} \\
\sigma_{i}^{2} & \sigma_{i}^{2}
\end{array}\right)
$$

I represent investor $i$ 's posterior beliefs of the terminal dividend $d$ given his signal as $N\left(m_{i 1} ; \sigma_{i 1}^{2}\right)$, hence the posterior of the investor $i$ at $t=1$ is $\varphi_{i 1}(d \mid y) \sim N\left(m_{i 1}, \sigma_{i 1}^{2}\right)$, where

$$
\begin{aligned}
m_{i 1} & =m_{i}+\sigma_{i}^{2}\left(\sigma_{i}^{2}+\sigma_{\varepsilon}^{2}\right)^{-1}\left(y-m_{i}\right), \\
\sigma_{i 1}^{2} & =\sigma_{i}^{2}-\sigma_{i}^{2}\left(\sigma_{i}^{2}+\sigma_{\varepsilon}^{2}\right)^{-1} \sigma_{i}^{2} .
\end{aligned}
$$

Therefore, the posterior mean, $m_{i 1}$, is a linear function of the investor's public signal, while the posterior variance, $\sigma_{i 1}^{2}$, only depends on the public information system and not on the specific signal.

Moreover, when the variance of the disturbance term $\sigma_{\varepsilon}^{2} \rightarrow 0$, the posterior mean $m_{i 1} \rightarrow y$, hence the posterior mean tend to be independent of the priors as public signal precision increases. When $\sigma_{\varepsilon}^{2} \rightarrow 0$, the posterior variance $\sigma_{i 1}^{2} \rightarrow 0$, this indicates that with higher public signal precision, investors are more confident on their inferences. When $\sigma_{\varepsilon}^{2} \rightarrow \infty$, the public signal disappears, thus the posterior beliefs equal to the prior beliefs. From 
the perspective of the investor $i$, the signal $y$ is normally distributed with $N\left(m_{i}, \sigma_{i}^{2}+\sigma_{\varepsilon}^{2}\right)$, hence the posterior mean $m_{i 1} \sim N\left(m_{i}, \sigma_{i}^{4}\left(\sigma_{i}^{2}+\sigma_{\varepsilon}^{2}\right)^{-1}\right)$. For further information on Bayesian learning model, see e.g., Raiffa and Schlaifer (1961) and DeGroot (1970).

\section{Equilibrium with Impact from Heterogeneity in Be- liefs and Strike Price: Benchmark Case when In- vestors Receive No or Perfect Public Signal}

In this section, I derive equilibriums in the economy populated with investors with heterogeneous beliefs. The investors can speculate in European call option markets. In order to see the effect of the heterogeneous beliefs and the strike price of European call options clearly without interruptions from the impact of the public information system, I first investigate a benchmark case in which the investors receive no or perfect public signal at $t=1$, then there is no basis for trading at $t=1$ based on posterior beliefs. Hence, the model is essentially equivalent to a single period model.

\subsection{Equilibrium in a Single Period Economy}

The payoff of a European call option with strike price $K$ at the date $t=2$ is $\max (d-K, 0)$, Hence, from the perspective of $t=0$, the date $t=2$ consumption for the investor $i$ is

$$
c_{i 2}=\theta_{i 0} \max (d-K, 0)+x_{i 0} d+\gamma_{i 0}
$$

Given the period-specific negative exponential utility, the investor $i$ s' date $t=0$ certainty equivalent of date $t=2$ consumption, receiving no or perfect public information at $t=1$, $\mathrm{CE}_{i 2}\left(\theta_{i 0}, x_{i 0}, \gamma_{i 0}\right)$ can be calculated according to Lemma 1.

Lemma 1 Assume the investors receive no or perfect public information at $t=1$, given the portfolios in the underlying asset markets, the call option markets, and the zero-coupon bond markets at $t=0$, the investor $i$ 's $t=0$ certainty equivalent of $t=2$ consumption is

$$
\mathrm{CE}_{i 2}\left(\theta_{i 0}, x_{i 0}, \gamma_{i 0}\right)=\gamma_{i 0}+m_{i 0} x_{i 0}-\frac{1}{2} r \sigma_{i 0}^{2} x_{i 0}^{2}+f_{i}\left(x_{i 0}, \theta_{i 0}\right)
$$


where

$$
\begin{aligned}
f_{i}\left(x_{i 0}, \theta_{i 0}\right)= & -\frac{1}{r} \ln \left\{\Phi\left(\frac{K-\left(m_{i 0}-r \sigma_{i 0}^{2} x_{i 0}\right)}{\sigma_{i 0}}\right)\right. \\
& +\exp \left[-r \theta_{i 0}\left[-K+m_{i 0}-\frac{1}{2} r \sigma_{i 0}^{2} \theta_{i 0}-r \sigma_{i 0}^{2} x_{i 0}\right]\right] \\
& \left.\times\left(1-\Phi\left(\frac{K-\left(m_{i 0}-r \sigma_{i 0}^{2}\left(\theta_{i 0}+x_{i 0}\right)\right)}{\sigma_{i 0}}\right)\right)\right\},
\end{aligned}
$$

and $\Phi(\cdot)$ is the cumulative distribution function of the standard normal distribution.

Proof: See Appendix A.

The investor $i$ 's $t=0$ certainty equivalent equals to the date $t=0$ consumption, i.e.,

$$
\mathrm{CE}_{i 0}=c_{i 2}=d_{0} \bar{z}_{i}+\left(\bar{\theta}_{i}-\theta_{i 0}\right) \pi_{0}(\eta)+\left(\bar{\gamma}_{i}-\gamma_{i 0}\right) \beta_{0}+\left(\bar{z}_{i}-x_{i 0}\right) p_{0}(\eta)
$$

the investor $i$ 's decision problem at $t=0$ can be stated as follows

$$
\max _{\theta_{i 0}, \gamma_{i 0}, x_{i 0}}-\exp \left(-r \mathrm{CE}_{i 0}\right)-\exp (-\delta) \exp \left(-r \mathrm{CE}_{i 2}\right)
$$

To solve for the equilibrium, I first solve the investor $i$ 's optimal portfolio choice problem,

$$
\begin{aligned}
& \frac{\partial\left(-\exp \left(-r \mathrm{CE}_{i 0}\right)-\exp (-\delta) \exp \left(-r \mathrm{CE}_{i 2}\right)\right)}{\partial x_{i 0}}=0 \\
& \frac{\partial\left(-\exp \left(-r \mathrm{CE}_{i 0}\right)-\exp (-\delta) \exp \left(-r \mathrm{CE}_{i 2}\right)\right)}{\partial \theta_{i 0}}=0 \\
& \frac{\partial\left(-\exp \left(-r \mathrm{CE}_{i 0}\right)-\exp (-\delta) \exp \left(-r \mathrm{CE}_{i 2}\right)\right)}{\partial \gamma_{i 0}}=0 .
\end{aligned}
$$

More details of calculation of the first derivatives in the first-order condition are provided in Appendix A. The equilibrium portfolios and the prices are implicit solutions of the system of equations which arise from the first-order conditions for the portfolio of each asset, and the market clearing condition for each asset, i.e.,

$$
\sum_{i=1}^{I} \gamma_{i 0}=0, \quad \sum_{i=1}^{I} \theta_{i 0}=0, \text { and } \sum_{i=1}^{I} x_{i 0}=Z
$$

The implicit solutions of the equations are functions of the prior beliefs. In the following numerical example with two investors, there are nine equations with nine unknowns, i.e., the equilibrium portfolios in the underlying asset markets $x_{i 0}, x_{j 0}$, the equilibrium portfolios 
in the option markets, $\theta_{i 0}, \theta_{j 0}$, the equilibrium portfolios in the bond markets, $\gamma_{i 0}, \gamma_{j 0}$, the equilibrium price for the zero-coupon bond, $\beta_{0}$, the equilibrium price for the underlying asset, $p_{0}$, and the equilibrium price for the European call option, $\pi_{0}$. Given the value of the parameters such as the strike price, the prior mean and the prior variance, I can solve the equations numerically. The methods to further simplify the equations to nonlinear equations with only three unknowns and the algorithms to solve for the equilibrium numerically are described in Appendix A.

\subsection{The Impact of Heterogeneous Beliefs and Strike Price on As- set Pricing Properties}

In this section, I demonstrate how the heterogeneity in beliefs and the strike price of option affect the equilibrium prices at $t=0$ when the investors hold heterogeneous beliefs including heterogeneous prior means and/or heterogeneous prior variances.

Solving for the equilibrium, I find that with homogeneous prior variance, the investors do not trade in the option markets. This is because the Pareto efficient side-betting based on their disagreements about the mean can be achieved by trading only in the risky underlying asset and the zero-coupon bond at $t=0$. The model reduces to a single period benchmark case in which the investors only trade in the stock and the zero-coupon bond. Hence in this section, I only plot the asset pricing properties such as the equilibrium interest rate and the equilibrium asset prices as functions of heterogeneity in prior precision, to study the impact of the heterogeneous beliefs in the option market. Moreover, I plot the asset pricing properties as functions of the strike price to detect the effect of strike price in option markets.

\subsubsection{Equilibrium Interest Rate}

The equilibrium interest rate in the single period is defined as $\iota \equiv-\ln \beta_{0}$. By the investor $i$ 's decision problem, i.e., Eq. (6), and the investor $i$ 's certainty equivalents at $t=0$ and

$t=2$, i.e., Eq. (5) and Eq. (4), the first-order condition with respect to the portfolio in the zero-coupon bond is given as

$$
-r \exp \left(-r \mathrm{CE}_{i 0}\right) \beta_{0}+r \exp (-\delta) \exp \left(-r \mathrm{CE}_{i 2}\right)=0
$$

Solve for the price of zero-coupon bond, I obtain

$$
\beta_{0}=\exp \left(-\left(\delta+r\left(\mathrm{CE}_{i 2}-\mathrm{CE}_{i 0}\right)\right)\right)
$$


With the definition of the equilibrium interest rate, I achieve the following proposition.

Proposition 1 Assume the investors with heterogeneous beliefs can potentially trade in option markets. The equilibrium interest rate is given as the time discount rate plus the riskadjusted growth in certainty equivalents, i.e.,

$$
\iota=\delta+r\left(\mathrm{CE}_{i 2}-\mathrm{CE}_{i 0}\right)
$$

In Eq. (7), the equilibrium interest rate is expressed as an increasing linear function of the growth in the investors' certainty equivalents. In equilibrium, due to the assumptions of common constant absolute risk aversion parameter $r$ and common utility discount rate $\delta$, it directly follows from the first-order condition that all the investors have the same growth in certainty equivalents. Note an identical relationship between the equilibrium interest rate and growth in certainty equivalents can be found in the benchmark model in Christensen and Qin (2012).

\begin{tabular}{cccc}
\hline & Investor $i$ & Investor $j$ & Aggregate \\
\hline Risk aversion $(r)$ & 0.8 & 0.8 & \\
Utility discount rate $(\delta)$ & 0.01 & 0.01 & \\
Prior mean $\left(m_{i}\right)$ & 0.01 & 0.01 & \\
Initial endowments of call option $\left(\bar{\theta}_{i}\right)$ & 0 & 0 & 0 \\
Initial endowments of zero-coupon bond $\left(\bar{\gamma}_{i}\right)$ & 0 & 0 & 0.0062 \\
Initial dividend $\left(d_{0}\right)$ & & & 20 \\
Supply $(Z)$ & 10 & 10 & \\
\hline
\end{tabular}

Table 1: Investor and risky asset parameters of the running example.

The equilibrium interest rate is endogenized in the equilibrium as a function of the prior precision and the strike price. To see the impact of those two pricing factors, and I plot the equilibrium interest rate as a function of heterogeneous prior precision at a fixed level of the strike price, and as a function of the strike price at a given level of the heterogeneity in beliefs in Figure 1 for the parameters in Table 1. Note the parameters are selected to guarantee: First, significant variations in both the level of equilibrium interest rate (from $3 \%$ to $6 \%$ in Figure 1) and equilibrium risk premium; Second, the scale of both the equilibrium interest rate and the equilibrium risk premium should be reasonable, e.g., the interest rate should be around $5 \%$, and the risk premium should be around 10\%; Third, considerably high accuracy of the numerical solutions of nonlinear equation within an acceptable computing time. Also note the general equilibrium properties which are analyzed in this paper maintain effective 
regardless the change of the parameters, given the parameters meet basic requirements, for instance, the risk aversion $r>0$, and the prior variance $\sigma_{i}^{2}>0$.
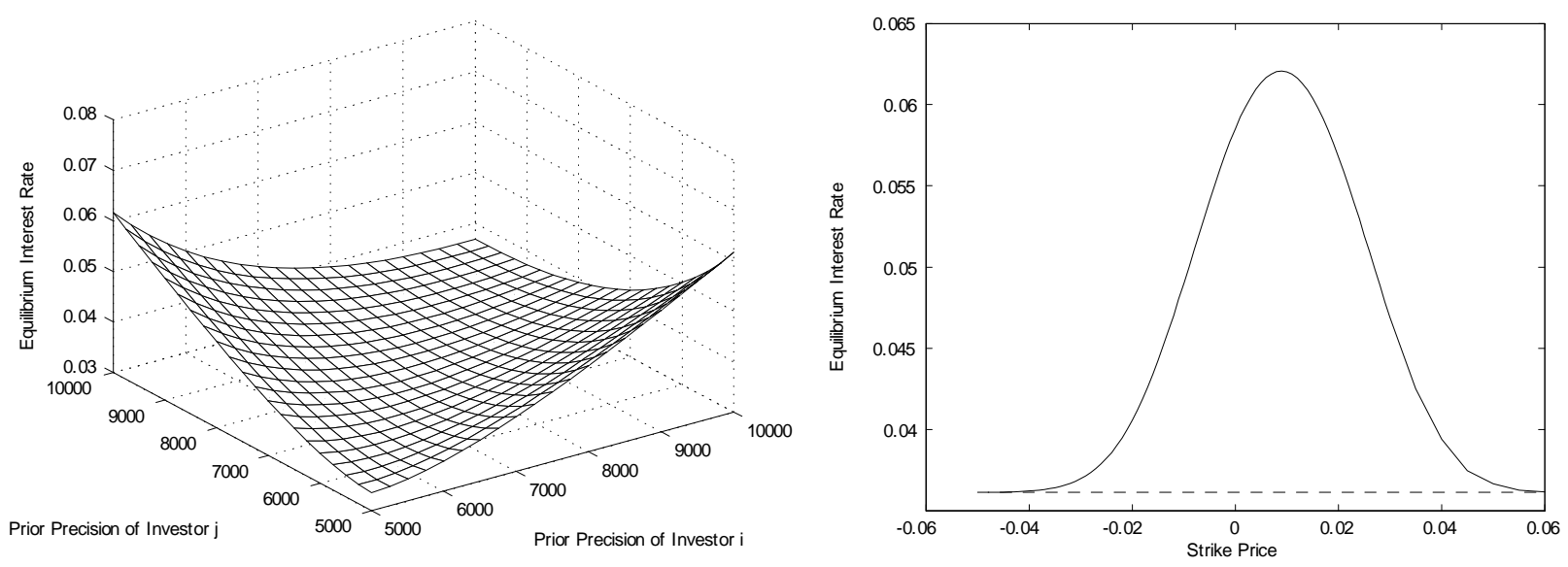

Figure 1. The Equilibrium Interest Rate. The equilibrium interest rate is plotted as a function of the heterogeneity in prior precision conditional on a given level of the strike price and the strike price conditional on a given level of the heterogeneity in prior precision. The horizon axes of the left panel indicate two investors' beliefs on the prior precision. I set the strike price $K=0.01$ when plotting the equilibrium interest rate as function of the heterogeneous beliefs. When plotting the equilibrium interest rate as function of the strike price, the prior variances are set to be $\sigma_{i}^{2}=$ $0.0002 ; \sigma_{j}^{2}=0.0001$. I use identical value of parameters for plotting other asset pricing properties in section 3.2, and thus do not repeat those parameter values again.

In each panel, when I plot the asset pricing properties as functions of the heterogeneity in beliefs, a diagonal line indicates that the two investors agree with each other, and depart further from the diagonal line indicates higher heterogeneity in beliefs. As we can see from the left panel of Figure 1, the equilibrium interest rate increases with the heterogeneity in prior precision. Since conditional on identical average prior precision, the higher heterogeneity in beliefs, the more opportunity in speculation in option market, and the more advantage of the disagreements and the differences in confidence among the investors can be taken. This effect leads to a higher efficiency of side-betting and more gains in trading. The trading gains translate into increased certainty equivalents of the $t=2$ consumption, and result in a higher equilibrium consumption growth, and thus a higher equilibrium interest rate. Note the increase of the equilibrium interest rate can be viewed as an analog of the side-betting trading gains. This intuition can be gained directly from Eq. (7). 
Furthermore, the diagonal line in the left panel shows that when investors hold homogeneous prior precision, the equilibrium interest rate increases with the prior precision. It is a standard result that with homogeneous belief, the equilibrium interest rate is given as the time discount factors plus a risk-adjusted aggregate consumption growth minus a variance of risk-adjusted aggregate consumption. With homogeneous beliefs, the investors do not trade in the option markets, and the variance of risk-adjusted aggregate consumption decreases with the prior precision.

The right panel of Figure 1 shows the impact of the strike price on the equilibrium interest rate. When the strike price is very high, i.e., the option is very deep out of the money, the value of option is almost zero. When the strike price is much lower than the mean, i.e., the option is very deep in the money, the option resembles a stock paying a dividend with a very high mean but with identical prior variance as that of the underlying asset. As a result, from the right panel of Figure 1, we can see, with very high or very low strike price, the equilibrium interest rate converges to that in the benchmark case in which the investors only trade in a stock and a zero-coupon bond as depicted by the bottom line. This result illustrates the lowest efficiency of side-betting and benefit from the disagreement in the prior variance. When the option is slightly in the money with an intermediate strike price, it is substantially different from nothing or a stock. Thus the investors can effectively and actively speculate in the option markets. This kind of call option can facilitate side-betting, and thus enhance the growth in certainty equivalents and the equilibrium interest rate. With the used parameters, the equilibrium interest rate reaches the maximum point of around 0.062 at an intermediate strike price of around 0.01 .

Note that Buraschi and Jiltsov (2006) and David (2008) also plot asset pricing properties as functions of heterogeneity in beliefs. However, they solve for the equilibrium by constructing a representative agent utility through taking weight of the two different individual utilities, and the weight is stochastic and endogenized in the equilibrium as a function of the difference in beliefs. Hence the change of heterogeneity in beliefs results in the change of the value of the weight. However, when plotting the asset pricing properties as functions of the heterogeneity in beliefs, they fix the value of the weight at a certain level. Hence their approach to analyze the impacts of the heterogeneous beliefs can be considered to be conditional. Models in this paper study the asset pricing properties as functions of the heterogeneous beliefs, the strike price, and the public information quality unconditionally.

\subsubsection{Equilibrium Risk Premium}

Christensen and Qin (2012) define the (continuously compounded) expected rate of return $\mu^{x a}(\eta)$ using the beliefs implicit in the unambiguous ex ante equilibrium price of the risky 
underlying asset, i.e., $\varphi^{h}(d) \sim N\left(\bar{m}^{h}, \bar{\sigma}^{2}\right)$

$$
\exp \left(\mu^{x a}(\eta)\right) \equiv \frac{\bar{m}^{h}}{p_{0}(\eta)},
$$

where

$$
\bar{m}^{h} \equiv \frac{1}{I} \sum_{i=1}^{I} \frac{h_{i}}{\bar{h}} m_{i}, \quad \bar{h} \equiv \frac{1}{I} \sum_{i=1}^{I} h_{i}, \quad \bar{\sigma}^{2} \equiv \frac{1}{\bar{h}} .
$$

I define the expected rate of return in the same way, and obtain the equilibrium risk premium on the risky underlying asset $\varpi^{x a}=\mu^{x a}(\eta)-\iota$. Since the equilibrium interest rate is defined as $\iota \equiv-\ln \beta_{0}$ and the ex ante price of the underlying asset is a product of the equilibrium riskless discount factor and the risk-adjusted expected dividend, i.e., $p_{0}(\eta)=\beta_{0} \mathrm{E}^{Q}[d]$, hence the equilibrium risk premium $\varpi^{x a}=\ln \bar{m}^{h}-\ln \mathrm{E}^{Q}[d]$. The following subsection provides the expression for the risk-adjusted dividend $\mathrm{E}^{Q}[d]$.

In the benchmark model without the option, the equilibrium risk premium on the risky asset is only affected by the prior mean, the prior precision, the risk aversion and the net supplies of the risky asset. However, when the investors invest in the option markets, the equilibrium risk premium on the risky underlying asset is affected by the strike price. I plot the equilibrium risk premium as a function of heterogeneous prior precision at a fixed level of the strike price, and as a function of the strike price at a given level of the heterogeneity in beliefs in Figure 2.
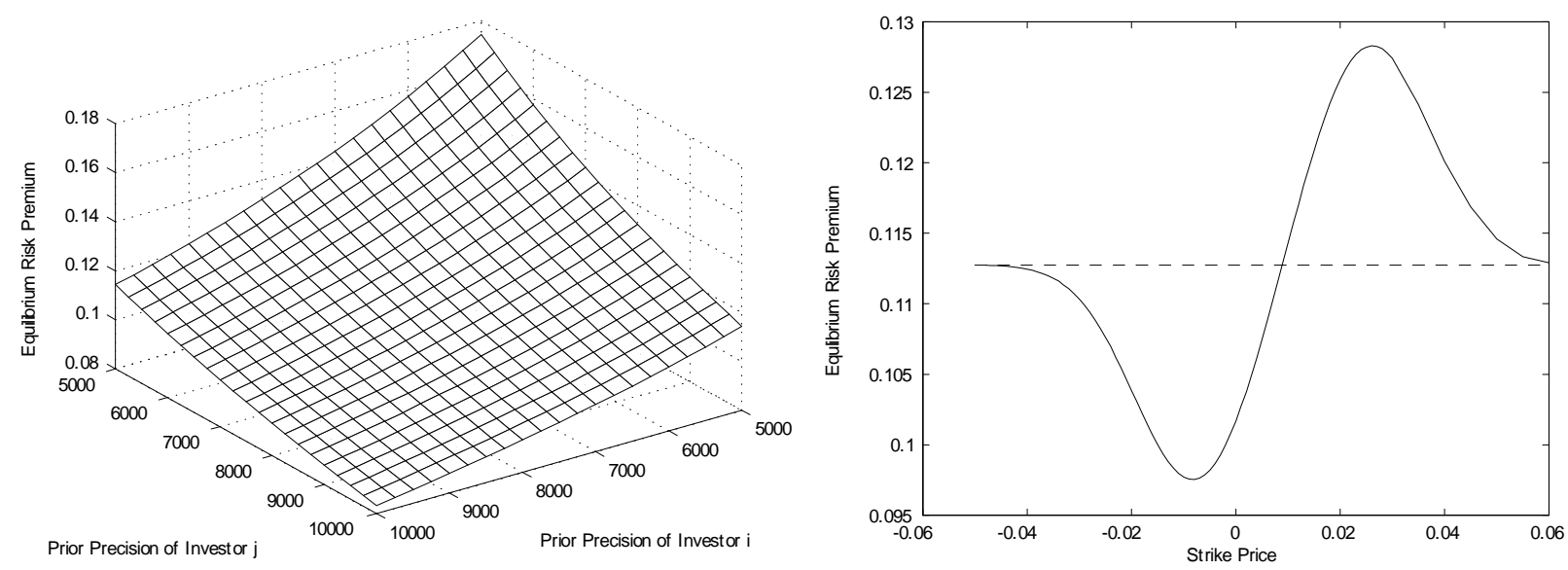

Figure 2. The Equilibrium Risk Premium. The equilibrium risk premium on the risky underlying asset is plotted as a function of the heterogeneous prior precision conditional on a given level of the strike price and the strike price conditional on a given level of the heterogeneity in prior precision. 
From the left panel in Figure 2, we can see the equilibrium risk premium is not affected by the heterogeneity in beliefs, but decreases with the average prior precision. With homogeneous prior precision, the investor's confidence on the forthcoming dividend increases with the prior precision, and thus decreases with the requirement of compensation for risk.

The curve in the right panel of Figure 2 is just like the inverted risk-adjusted expected dividend. With a fixed level of heterogeneous beliefs, when the strike price is much higher or much lower than the mean, the option resembles nothing or a stock. The equilibrium risk premium on the risky underlying asset converges to that in a benchmark case with a stock and a zero-coupon bond as depicted by the middle line. The intuition of the impact of the intermediate strike price can be gained from the fact that the risk-adjusted expected dividend is the expected dividend plus the covariance of the marginal utility of consumption and the dividend scaled by the expected marginal utility of consumption. See more in Chapter 5 in Christensen and Feltham (2003). Note in the right panel, when the strike price $K$ increases from -0.005 to 0.023 , the equilibrium risk premium increases. To understand this fact, I plot the marginal utility of consumption as a function of the realizations of forthcoming dividend in Figure 3.

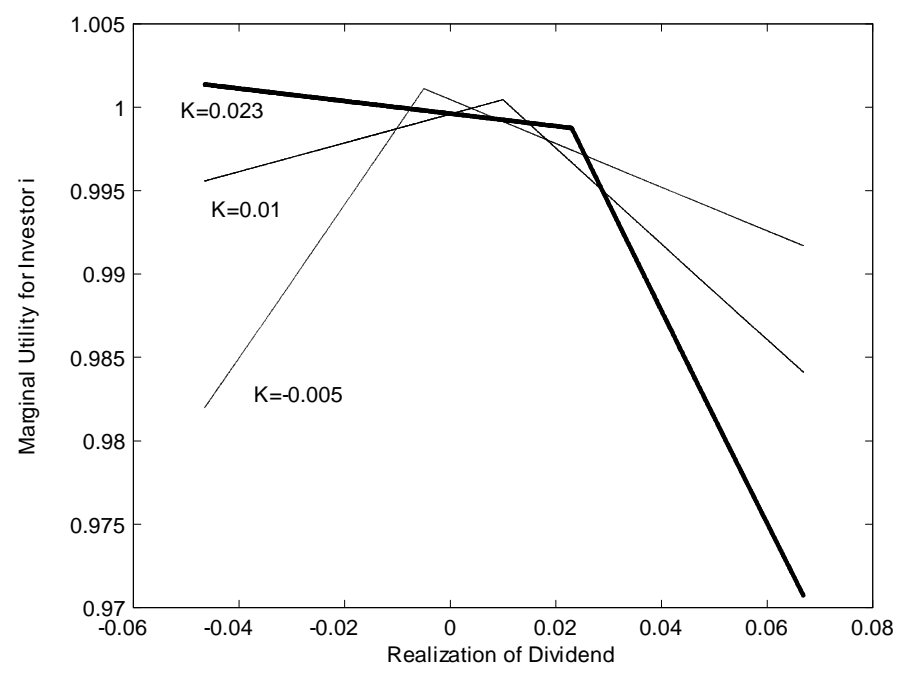

Figure 3. Marginal Utility of Consumption. The marginal utility of consumption is plotted as a function of the realizations of forthcoming dividend with the strike price $K=-0.005,0.01,0.023$ respectively.

We can see from Figure 3 that when the strike price $K$ increases from -0.005 to 0.023 , the slope of the broken line of marginal utility is in general decreasing, this fact signals the covariance of the marginal utility of consumption and the dividend is in general decreasing, thus the value of $\mathrm{E}^{Q}[d]$ decreases, and the equilibrium risk premium increases. 
Furthermore, the marginal utility of consumption is determined by the investors' portfolios. I plot the portfolios in financial markets as functions of the strike price in Figure 4 .
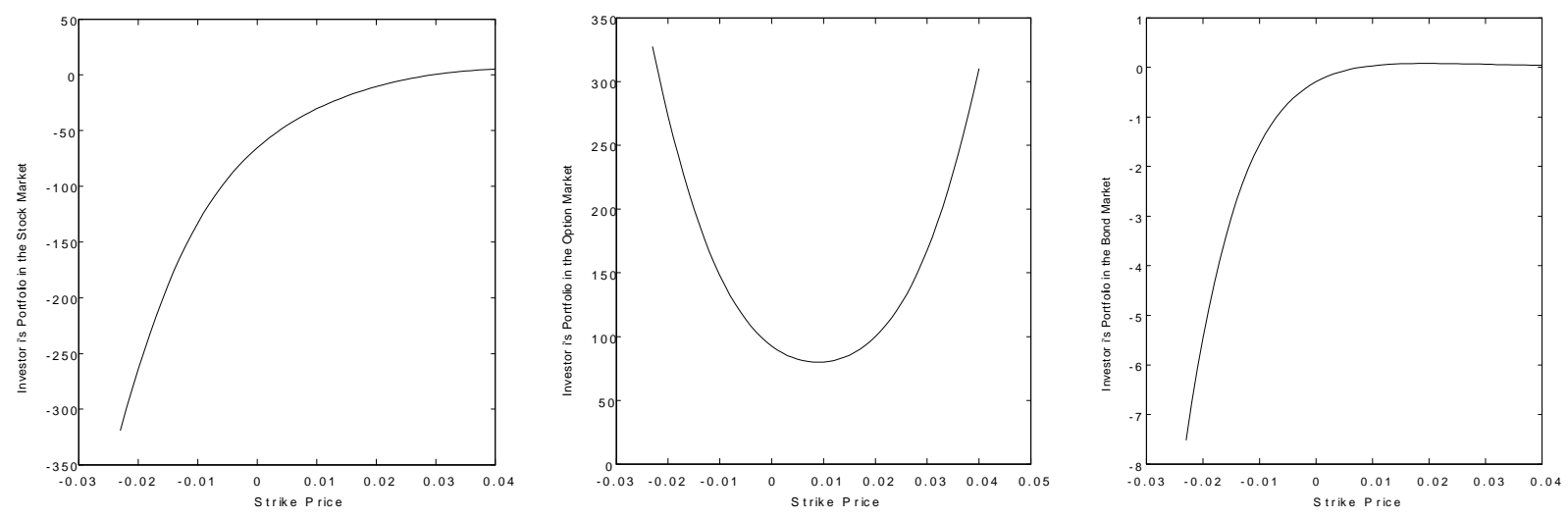

Figure 4. The Equilibrium Portfolios for Investor with Lower Prior Precision. The equilibrium portfolios for the investor with lower prior precision in the underlying asset markets, the option markets, the zero-coupon bond markets are plotted as a function of the strike price conditional on a certain level of heterogeneity in prior variance in the left panel, middle panel, and right panel, respectively.

An investor with low prior precision takes a positive position in the option market. Moreover, since with extreme strike price, the option tends to resemble stock or nothing, and thus has a payoff with little convexity. Therefore, from Figure 4 we can see that, in order to accumulate enough convexity, the investor takes a very high position in the option market. When the option is very deep in the money and resembles a stock, high positive demand in the option leads to a large short position in the stock market and bond market. Relatively, when the option is very out of the money and resembles nothing, the portfolio in the stock market and the bond market converges to that in the benchmark model in which investors only trade in a stock and a bond. The equilibrium portfolios give rise to the statedependent payoff according to Eq. (3), and thus the marginal utility which is a function of the forthcoming dividend.

\subsubsection{Equilibrium Price of Risky Underlying Asset}

The underlying asset price is endogenized in the equilibrium as a function of the priors and the strike price. I plot the equilibrium underlying asset price as a function of heterogeneous prior precision at a fixed level of the strike price, and as a function of the strike price at a 
given level of the heterogeneity in beliefs in Figure 5.
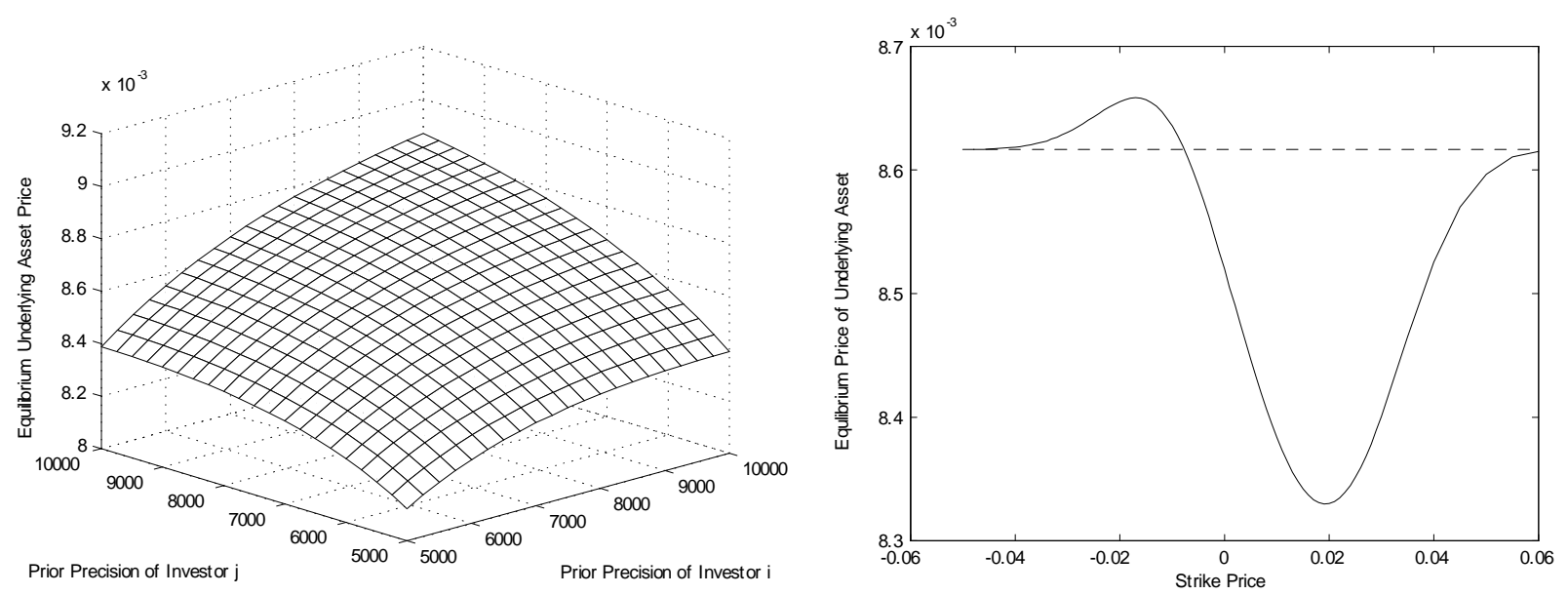

Figure 5. The Equilibrium Underlying Asset Price. The equilibrium underlying asset price is plotted as a function of the heterogeneous prior precision conditional on a given level of strike price and the strike price conditional on a given level of the heterogeneity in prior precision.

To analyze the properties of the underlying asset price, I first establish the following proposition by deriving the investors' first-order condition with respect to the portfolio in the underlying asset.

Proposition 2 Assume the investors with heterogeneous beliefs can potentially trade in option markets. The ex ante equilibrium price of the risky underlying asset at $t=0$ is equal to the equilibrium riskless discount factor times the risk-adjusted expected dividend, i.e.,

$$
p_{0}(\eta)=\beta_{0} \mathrm{E}^{Q}[d]
$$

The risk-adjusted expected dividend is expressed as a function of the prior means and variances, i.e., ${ }^{7}$

$$
\mathrm{E}^{Q}[d]=\left[\prod_{i=1}^{I} \frac{\partial \mathrm{CE}_{i 2}\left(\theta_{i 0}, x_{i 0}, \gamma_{i 0}\right)}{\partial x_{i 0}}\right]^{\frac{1}{I}}=\left[\prod_{i=1}^{I}\left(m_{i 0}-r \sigma_{i 0}^{2} x_{i 0}+\frac{\partial f_{i}\left(x_{i 0}, \theta_{i 0}\right)}{\partial x_{i 0}}\right)\right]^{\frac{1}{I}}
$$

${ }^{7}$ This means that I can define the risk-adjusted probability measure $Q$ explicitly such that under $Q$, the terminal dividend is normally distributed as $d \sim N\left(\left[\prod_{i=1}^{I} \frac{\partial \mathrm{CE}_{i 2}\left(\theta_{i 0}, x_{i 0}, \gamma_{i 0}\right)}{\partial x_{i 0}}\right]^{\frac{1}{I}}, \bar{\sigma}^{2}\right)$. Note that while the expected dividend under $Q$ is uniquely determined in equilibrium, the variance of the dividend under $Q$ is not uniquely determined due to the market incompleteness and, thus, I just take it to be $\bar{\sigma}^{2}$. Fortunately, the lack of the uniqueness of the variance has no consequences in the subsequent analysis. 
As the strike price varies, the ex ante equilibrium price of the risky underlying asset can either be higher or lower than that in the benchmark model in which investors trade only in a stock and a zero-coupon bond.

Proof. See Appendix A for details of the derivation of the equilibrium underlying asset price.

As indicated by Proposition 2, the left (right) panel in Figure 5 is a balanced result of the left (right) panel in Figure 1 and Figure 2. With the parameters I use, the price of the risky underlying asset decreases with the heterogeneity in beliefs. The diagonal line indicates that with homogeneous belief, the risky asset price increases with the prior precision.

Moreover, the right panel in Figure 5 shows that, with a fixed level of heterogeneous beliefs, when the strike price is much higher or much lower than the mean, the price of the risky underlying asset converges to that in a benchmark case with a risky asset and a zero-coupon bond as depicted by the middle line of around 8.62 .

\subsubsection{Equilibrium Call Option Price}

The European call option price is endogenized in the equilibrium as a function of the priors and the strike price. I plot the equilibrium call option price as a function of heterogeneous prior precision at a fixed level of the strike price, and as a function of the strike price at a given level of the heterogeneity in beliefs in Figure 6 .
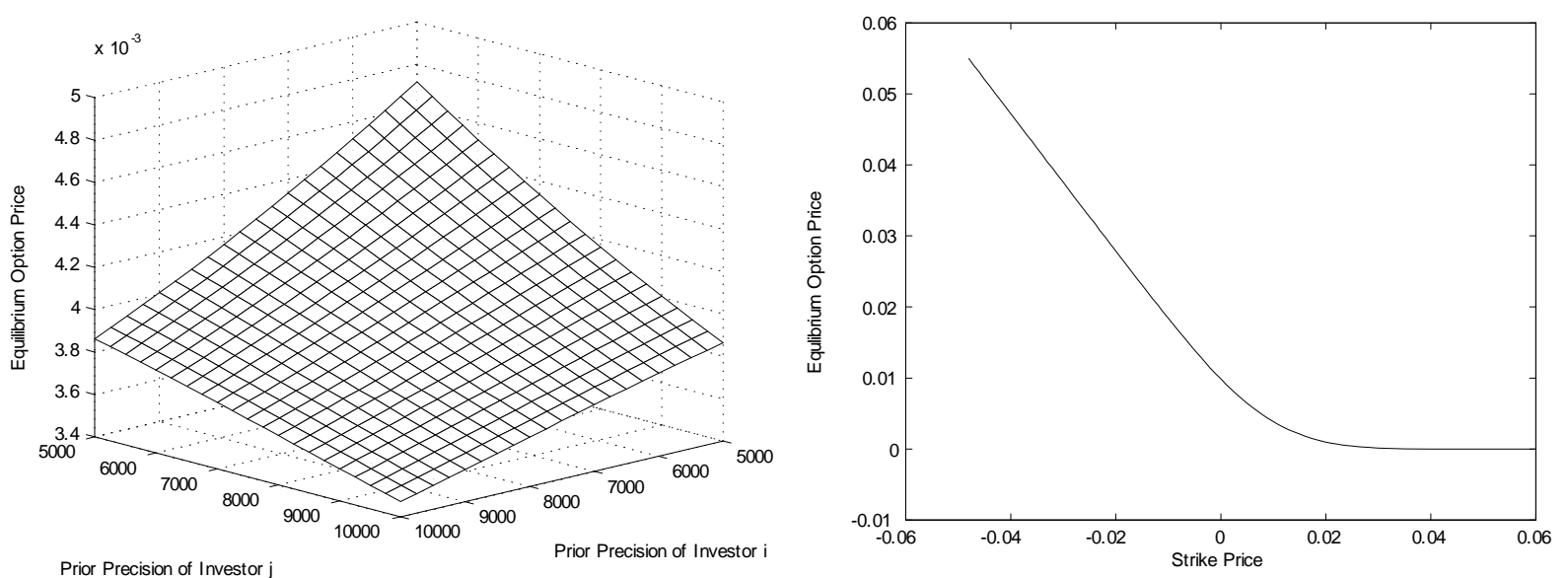

Figure 6. The Equilibrium Call Option Price. The equilibrium call option price is plotted as a function of the heterogeneity in beliefs conditional on a given level of strike price and the strike price conditional on a given level of the heterogeneity in prior precision. 
Similar to the case of the equilibrium underlying asset price, to analyze the option price, I establish the following proposition by deriving the investors' first-order condition with respect to the portfolio in the call option.

Proposition 3 Assume the investors with heterogeneous beliefs can potentially trade in option markets. The ex ante equilibrium price of the European call option at $t=0$ is equal to the equilibrium riskless discount factor times the risk-adjusted expected option payment, i.e.,

$$
\pi_{0}(\eta)=\beta_{0} \mathrm{E}^{Q}[\max (d-K, 0)]
$$

The risk-adjusted expected dividend is expressed as a function of the prior means and variances, i.e.,

$$
\mathrm{E}^{Q}[\max (d-K, 0)]=\left[\prod_{i=1}^{I} \frac{\partial \mathrm{CE}_{i 2}\left(\theta_{i 0}, x_{i 0}, \gamma_{i 0}\right)}{\partial \theta_{i 0}}\right]^{\frac{1}{I}}=\left[\prod_{i=1}^{I} \frac{\partial f_{i}\left(x_{i 0}, \theta_{i 0}\right)}{\partial \theta_{i 0}}\right]^{\frac{1}{I}}
$$

As we can see from the left panel in Figure 6, with the parameters I use, the impact of the heterogeneity in beliefs on the equilibrium call option price is almost invisible. The diagonal line indicates that with homogeneous prior precision, the equilibrium call option price decreases with the prior precision. In this case, the investors do not trade in the option markets, and the option is a redundant asset. The model reduces to a benchmark case that matches the result of the Black-Scholes model: The higher stock volatility, the higher value of the option.

Moreover, the right panel in Figure 6 shows that, of course, the deeper in the money, the more valuable the option is. When the option is very deep out of the money, the equilibrium call option price is nearly zero.

\subsubsection{Equilibrium Expected Utilities}

The impact of the option on individual utility is similar to that of public signal precision in Christensen and Qin (2012), hence I only clarify the underlying mechanism concisely. The investors' ex ante expected utilities are affected in two ways by changes of the strike price. First, changes in the strike price affects the gains to trade based on heterogeneously updated posterior beliefs and, thus, the growth in their certainty equivalents. Secondly, the strike

price affects the ex ante equilibrium asset prices through the equilibrium interest rate and the equilibrium risk premium and, thus, affects the value of the investors' individual endowments. The latter may affect the investors in different ways depending on their individual endowments relative to their equilibrium portfolio at $t=0$. Therefore, the investors may not 
unanimously prefer the option with an intermediate strike price. Since a low equilibrium asset price is of course good if the investor want to reduce the holding of the asset at $t=1$, but it is bad if the investor wants to reduce the holding of the asset. However, with equilibrium endowments of the market security, the equilibrium prices are independent of the investors' individual endowments, the investors do not trade at $t=0$ given these endowments, all the investors can benefit from the option with an intermediate strike price.

\section{Equilibrium with Impact from Heterogeneity in Be- liefs, Strike Price and Public Signal: Case when In- vestors Update Beliefs with Imperfect Public Signal}

In this section, I numerically solve for the ex ante equilibrium in a two-period economy in which investors can update their beliefs according to the Bayes' rule with imperfect public signal. There are two rounds of trading: one round of trading at $t=0$ prior to the release of the information, and a second round of trading subsequent to the release of the public signal $y$ at $t=1$. I solve for the ex ante equilibrium by first deriving the ex post equilibrium prices at $t=1$, and given this ex post equilibriums, I can subsequently derive the ex ante equilibrium prices at $t=0$.

\subsection{Ex Post Equilibrium at Date $t=1$}

I first derive the ex post equilibrium at $t=2$ conditional on the posterior beliefs. From the perspective of $t=1$, date $t=2$ consumption for the investor $i$ is

$$
c_{i 2}=\theta_{i 1}(y) \max (d-K, 0)+x_{i 1}(y) d+\gamma_{i 1}(y)
$$

Given the period-specific negative exponential utility, the investor $i$ maximizes his certainty equivalent of $t=2$ consumption conditional on the public information at $t=1$, subject to his budget constraint, i.e.,

$$
\max _{\theta_{i 1}(y), x_{i 1}(y), \gamma_{i 1}(y)} \mathrm{CE}_{i 2}\left(\theta_{i 1}(y), x_{i 1}(y), \gamma_{i 1}(y) \mid m_{i 1}, \sigma_{i 1}^{2}\right)
$$

subject to $\beta_{1} \gamma_{i 1}(y)+p_{1}(y) x_{i 1}(y)+\pi_{1}(y) \theta_{i 1}(y) \leq \beta_{1} \gamma_{i 0}+p_{1}(y) x_{i 0}+\pi_{1}(y) \theta_{i 0}$, where $\mathrm{CE}_{i 2}\left(\theta_{i 1}(y), x_{i 1}(y), \gamma_{i 1}(y) \mid m_{i 1}, \sigma_{i 1}^{2}\right)$ can be calculated by Lemma 1.

The ex post certainty equivalent of $t=2$ consumption of the investor $i$ conditional on 
the public information at $t=1$ is

$$
\begin{aligned}
& \mathrm{CE}_{i 2}\left(\theta_{i 1}(y), x_{i 1}(y), \gamma_{i 1}(y) \mid m_{i 1}, \sigma_{i 1}^{2}\right) \\
= & \gamma_{i 1}(y)+m_{i 1} x_{i 1}(y)-\frac{1}{2} r \sigma_{i 1}^{2} x_{i 1}^{2}(y)+f_{i}\left(x_{i 1}, \theta_{i 1}\right),
\end{aligned}
$$

where

$$
\begin{aligned}
f_{i}\left(x_{i 1}(y), \theta_{i 1}(y)\right)= & -\frac{1}{r} \ln \left\{\Phi\left(\frac{K-\left(m_{i 1}-r \sigma_{i 1}^{2} x_{i 1}(y)\right)}{\sigma_{i 1}}\right)\right. \\
& +\exp \left[-r \theta_{i 1}(y)\left[-K+m_{i 1}-\frac{1}{2} r \sigma_{i 1}^{2} \theta_{i 1}(y)-r \sigma_{i 1}^{2} x_{i 1}(y)\right]\right] \\
& \left.\times\left(1-\Phi\left(\frac{K-\left(m_{i 1}-r \sigma_{i 1}^{2}\left(\theta_{i 1}(y)+x_{i 1}(y)\right)\right)}{\sigma_{i 1}}\right)\right)\right\},
\end{aligned}
$$

and $\Phi(\cdot)$ is the cumulative distribution function of the standard normal distribution.

Assume $\beta_{1}=1$ as the numeraire in the model, I solve the investor $i$ 's optimal portfolio choice problem. The equilibrium portfolios and the prices are the implicit solutions of the system of equations which arise from the first-order conditions for the portfolio of each asset,

$$
\begin{gathered}
m_{i 1}-r \sigma_{i 1}^{2} x_{i 1}(y)+\frac{\partial f_{i}\left(x_{i 1}(y), \theta_{i 1}(y)\right)}{\partial x_{i 1}}-p_{1}(y)=0 \\
\frac{\partial f_{i}\left(x_{i 1}(y), \theta_{i 1}(y)\right)}{\partial \theta_{i 1}}-\pi_{1}(y)=0
\end{gathered}
$$

and the market clearing condition for each asset, i.e.,

$$
\sum_{i=1}^{I} \theta_{i 1}(y)=0, \text { and } \sum_{i=1}^{I} x_{i 1}(y)=Z \text {. }
$$

Note the implicit solutions are functions of the public signal $y$, the public signal precision, the strike price, and the posterior beliefs (hence the prior beliefs). In the numerical example with two investors, there are six equations with six unknowns, i.e., the ex post equilibrium portfolios in the underlying asset markets, $x_{i 1}(y), x_{j 1}(y)$, the ex post equilibrium portfolios in the option markets, $\theta_{i 1}(y), \theta_{j 1}(y)$, the ex post equilibrium price for the underlying asset, $p_{1}(y)$, and the ex post equilibrium price for the option, $\pi_{1}(y)$. Given the public signal $y$, the signal precision and the prior beliefs, I can solve the equations numerically. The methods to further simplify the equations to the nonlinear equations with only two unknowns and the algorithms to solve for the equilibrium numerically are described in Appendix A. 


\subsection{Ex Ante Equilibrium at Date $t=0$}

I now determine the ex ante equilibrium price and the demands for assets functions at $t=0$, taking the equilibrium at $t=1$ characterized by the system of equations, i.e., Eq. (12a), Eq. $(12 \mathrm{~b})$, and Eq. (12c) as given. From the perspective of $t=0$, the date $t=2$ consumption for the investor $i$ is

$$
\begin{aligned}
c_{i 2}= & \theta_{i 1}(y)\left(\max (d-K, 0)-\pi_{1}(y)\right)+\theta_{i 0} \pi_{1}(\eta) \\
& +x_{i 1}(y)\left(d-p_{1}(y)\right)+x_{i 0} p_{1}(y)+\gamma_{i 0} \\
= & \theta_{i 1}(y) \max (d-K, 0)+x_{i 1}(y) d \\
& +\left(\theta_{i 0}-\theta_{i 1}(y)\right) \pi_{1}(y)+\left(x_{i 0}-x_{i 1}(y)\right) p_{1}(y)+\gamma_{i 0} .
\end{aligned}
$$

By Lemma 1, conditional on the public information at $t=1$, the investor $i$ 's certainty equivalent of $t=2$ consumption is

$$
\begin{aligned}
& \mathrm{CE}_{i 2}\left(x_{i 0}, \theta_{i 0}, \gamma_{i 0}, p_{0}, \beta_{0}, \pi_{0}, x_{i 1}(y), \theta_{i 1}(y), p_{1}(y), \pi_{1}(y) \mid \mathcal{F}_{1}\right) \\
= & \left(\theta_{i 0}-\theta_{i 1}(y)\right) \pi_{1}(y)+\left(x_{i 0}-x_{i 1}(y)\right) p_{1}(y) \\
& +\gamma_{i 0}+m_{i 1} x_{i 1}(y)-\frac{1}{2} r \sigma_{i 1}^{2} x_{i 1}^{2}(y) \\
& -\frac{1}{r} \ln \left\{\Phi\left(\frac{K-\left(m_{i 1}-r \sigma_{i 1}^{2} x_{i 1}(y)\right)}{\sigma_{i 1}}\right)\right. \\
& +\exp \left[-r \theta_{i 1}(y)\left[-K+m_{i 1}-\frac{1}{2} r \sigma_{i 1}^{2} \theta_{i 1}(y)-r \sigma_{i 1}^{2} x_{i 1}(y)\right]\right] \\
& \left.\times\left(1-\Phi\left(\frac{K-\left(m_{i 1}-r \sigma_{i 1}^{2}\left(\theta_{i 1}(y)+x_{i 1}(y)\right)\right)}{\sigma_{i 1}}\right)\right)\right\}
\end{aligned}
$$

where $\mathcal{F}_{1}$ denotes the investors' public information at date $t=1$.

Conditional on the information at $t=1$, the investor $i$ 's certainty equivalent of $t=2$ consumption varies with the investors' posterior mean $m_{i 1}$, and thus by Eq. (1), is a function of the public signal $y$. From the perspective of investor $i, y \sim N\left(m_{i}, \sigma_{i}^{2}+\sigma_{\varepsilon}^{2}\right)$. Given each realization of the public signal $y$, I can solve for the ex post equilibrium and obtain the $e x$ post equilibrium prices and demands at $t=1$ numerically. Substituting in the equilibrium prices and demands at $t=1$ conditional on each public signal $y$, the expected utility at $t=2$ from the perspective of $t=0$ can be written as

$$
\begin{aligned}
& -\mathrm{E}\left[\exp \left[-r \mathrm{CE}_{i 2}\left(x_{i 0}, \theta_{i 0}, \gamma_{i 0}, \beta_{0}, p_{0}, \pi_{0}, x_{i 1}(y), \theta_{i 1}(y), p_{1}(y), \pi_{1}(y) \mid \mathcal{F}_{1}\right)\right]\right] \\
= & -\frac{1}{\sqrt{2 \pi\left(\sigma_{i}^{2}+\sigma_{\varepsilon}^{2}\right)}} \int_{-\infty}^{+\infty} \exp \left[-r \mathrm{CE}_{i 2}(y)\right] \exp \left(-\frac{\left(m_{i}-y\right)^{2}}{2\left(\sigma_{i}^{2}+\sigma_{\varepsilon}^{2}\right)}\right) d y .
\end{aligned}
$$


Note the expected utility is a function of the ex ante equilibrium portfolios, $\gamma_{i 0}, x_{i 0}, \theta_{i 0}$, the priors $m_{i}, \sigma_{i}^{2}$, and the public signal precision $h_{\varepsilon}$. The expected utility is a deterministic integral over the infinite interval, and thus can be computed at any desired level of accuracy using standard numerical integration methods (See more about the numerical integration methods in the Appendix A).

The investor $i$ 's $t=0$ certainty equivalent equals to the date $t=0$ consumption, i.e.,

$$
\mathrm{CE}_{i 0}=c_{i 0}=d_{0} \bar{z}_{i}+\left(\bar{\theta}_{i}-\theta_{i 0}\right) \pi_{0}(\eta)+\left(\bar{\gamma}_{i}-\gamma_{i 0}\right) \beta_{0}+\left(\bar{z}_{i}-x_{i 0}\right) p_{0}(\eta),
$$

hence the investor $i$ 's decision problem at $t=0$ can be stated as follows

$$
\max _{\theta_{i 0}, \gamma_{i 0}, x_{i 0}}-\exp \left(-r \mathrm{CE}_{i 0}\right)-\exp (-\delta) \exp \left(-r \mathrm{CE}_{i 2}\right) .
$$

Solve the investor $i$ 's optimal portfolio choice problem, the ex ante equilibrium portfolios and the prices are implicit solutions of the system of equations which arise from the first-order conditions for the portfolio of each asset, i.e.,

$$
\begin{aligned}
& \frac{\partial\left(-\exp \left(-r \mathrm{CE}_{i 0}\right)-\exp (-\delta) \exp \left(-r \mathrm{CE}_{i 2}\right)\right)}{\partial x_{i 0}}=0 \\
& \frac{\partial\left(-\exp \left(-r \mathrm{CE}_{i 0}\right)-\exp (-\delta) \exp \left(-r \mathrm{CE}_{i 2}\right)\right)}{\partial \theta_{i 0}}=0 \\
& \frac{\partial\left(-\exp \left(-r \mathrm{CE}_{i 0}\right)-\exp (-\delta) \exp \left(-r \mathrm{CE}_{i 2}\right)\right)}{\partial \gamma_{i 0}}=0
\end{aligned}
$$

and the market clearing condition for each asset, i.e.,

$$
\sum_{i=1}^{I} \gamma_{i 0}=0, \quad \sum_{i=1}^{I} \theta_{i 0}=0, \text { and } \sum_{i=1}^{I} x_{i 0}=Z .
$$

Note the implicit solutions are functions of the public signal precision, the strike price, and the prior beliefs. In a two-investor model, there are nine equations with nine unknowns, as we have seen in benchmark model in section 3.1.1. The ex ante equilibrium can be solved for numerically.

\subsection{The Impact of Heterogeneous Beliefs, Strike Price and Public Signal Precision on Ex Ante Asset Pricing Properties}

When the investors update their beliefs with imperfect public signal precision, the public information system shows its influence in facilitating side-betting. Solving for the ex ante 
equilibrium, I find that when the investors receive no public signal or perfect public signal, the model reduces to the benchmark model in which the investors speculate in the option markets in the previous section. Moreover, with homogeneous prior variance, the investors do not trade in the option markets, and asset pricing is independent of the public information system. The intuition is similar to that in the benchmark model, i.e., trading in the underlying asset and the zero-coupon bond is already able to facilitate efficient side-betting.

Furthermore, conditional on a certain level of the public signal precision and the strike price, the impact of the heterogeneous beliefs on the asset pricing properties is quite similar to that in the previous section. The figures and intuition of the panels are almost the same. Thus I do not repeat those results including pictures and explanations again. Therefore in this section, I only plot the asset pricing properties as functions of the public signal precision and the strike price conditional on a certain level of heterogeneity in beliefs.

\subsubsection{Ex Ante Equilibrium Interest Rate}

The ex ante equilibrium interest rate from $t=0$ to $t=2$ is defined as $\iota \equiv-\ln \beta_{0}$. By the investor $i$ 's decision problem in Eq. (15), and the expression of the investor $i$ 's certainty equivalents at $t=0$ and $t=2$, i.e., Eq. (13) and Eq. (14), the relationship between the equilibrium interest rate and the growth in certainty equivalents in Eq. (7) still establishes.

The ex ante equilibrium interest rate is endogenized in the equilibrium as a function of the priors, the public signal precision and the strike price. To see the impact of the strike price and the public information quality, and I plot the ex ante equilibrium interest rate as a function of the strike price and the public signal precision conditional on a certain level of heterogeneity in the prior variance in Figure 7.
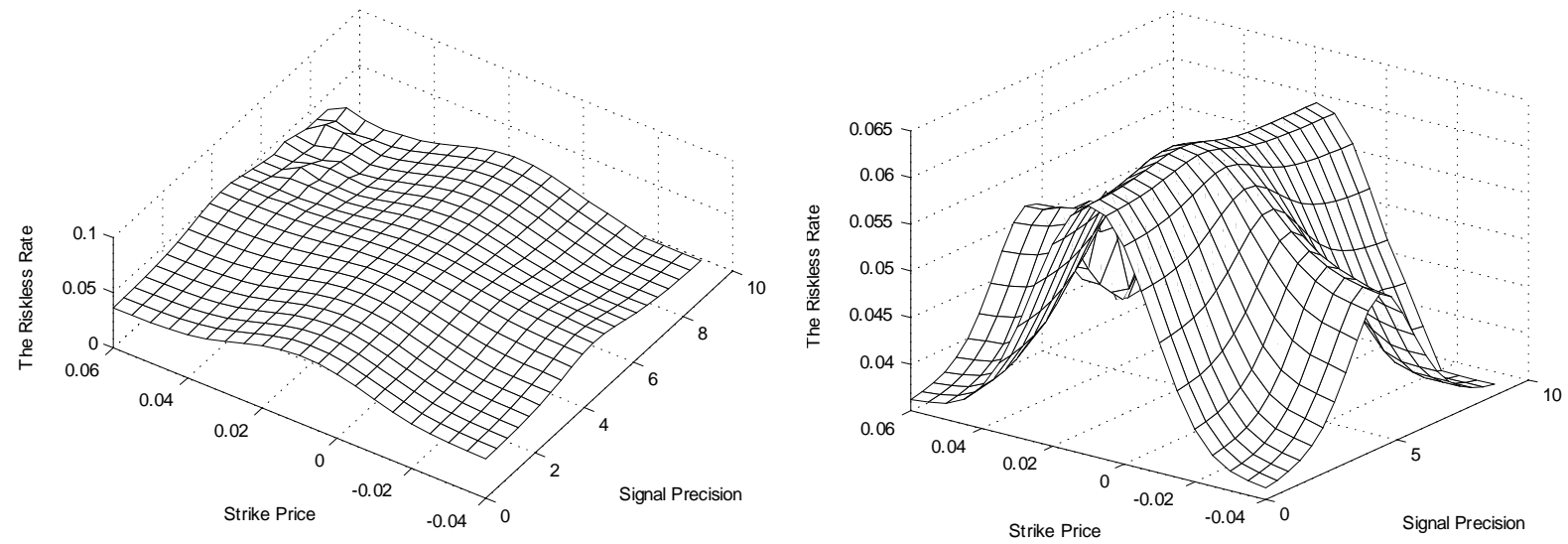

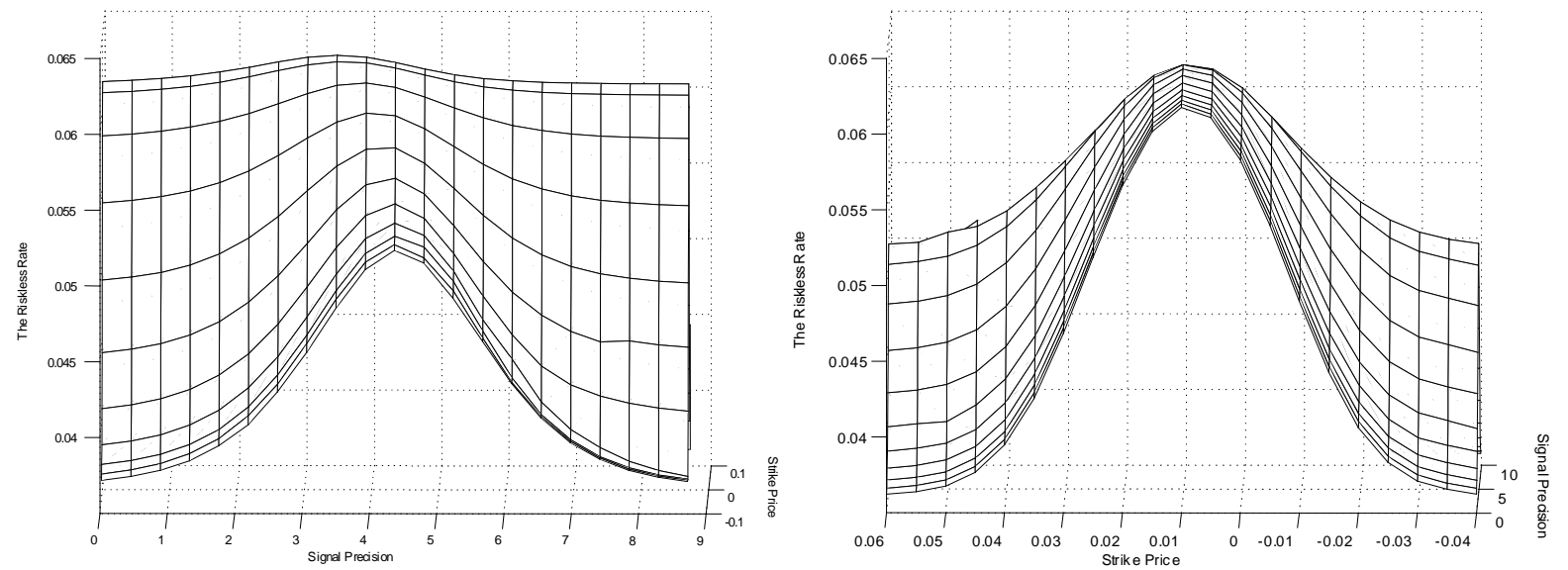

Figure 7. The Ex Ante Equilibrium Interest Rate. The ex ante equilibrium interest rate is plotted as a function of the strike price and the public signal precision conditional on a certain level of heterogeneity in the prior variance. The scale on the axis of the public signal precision is $x=\ln \left(1+0.005 h_{\varepsilon}\right)$. The parameters used when plotting are presented in Table 1 , in addition to the prior variances $\sigma_{i}^{2}=0.0002 ; \sigma_{j}^{2}=0.0001$. I use identical value of the parameters for plotting other asset pricing properties throughout this section, and do not repeat the parameter values again.

The above panels in Figure 7 indicates that, the option and the public signal precision enable the investors to achieve improved side-betting based on their heterogeneously updated posterior beliefs. These gains to trade translate into increased certainty equivalents of $t=2$ equilibrium consumption and, thus, a higher growth in their certainty equivalents and the $e x$ ante equilibrium interest rate. With an intermediate public signal precision and the option with an intermediate strike price, the highest efficiency of side-betting is achieved, reflected by the unique maximum point of the ex ante equilibrium interest rate.

The left below panel in Figure 7 shows the ex ante equilibrium interest rate surface from a special angle by which we can see, conditional on a certain level of the public signal precision, the $e x$ ante equilibrium interest rate is bell-shaped with respect to the strike price. Since with very low or very high strike price, the option payment is similar to a stock or nothing, thus the option's ability to facilitate side-betting is limited. However, with an intermediate strike price, the option distinguishes from a fixed income asset and a stock. This kind of option can enhance the market allocational efficiency to the best degree and, thus, leads to the highest growth in certainty equivalents and the highest equilibrium interest rate. Moreover, we can see that when the public signal precision changes from 0 to 10 , conditional on each fixed public signal precision, the extreme point of the strike price is always at around 0.009 . This result indicates that the extreme point of the ex ante equilibrium interest rate surface is 
independent of the public signal precision. This finding matches the result in the benchmark model in Christensen and Qin (2012).

The right below panel in Figure 7 shows the ex ante equilibrium interest rate surface from a special angle by which we can see, conditional on a certain level of the strike price, the ex ante equilibrium interest rate is bell-shaped with respect to the public signal precision. ${ }^{8}$ Furthermore, when the strike price changes from -0.04 to 0.01 , conditional on each fixed level of the strike price, the extreme point of the public signal precision moves from around 3.5 to around 4.5. This result indicates that the extreme point of the ex ante equilibrium interest rate surface is a function of the strike price.

The intuition for the fact that the ex ante equilibrium interest rate is bell-shaped with respect to public signal precision conditional on a certain level of the strike price can be gained from Eq. (7). Actually, the equilibrium consumption growth is bell-shaped with respect to the public signal precision.

With a given level of heterogeneity in priors, the public signal precision has two countervailing effects on equilibrium interest rate. The first type effect is that when the public signal precision is very low, a better public information quality tends to give rise to more efficient side-betting based on the updated beliefs, and results in a higher equilibrium interest rate. However, when the public signal precision is very high, the investors tend to have very similar inference at $t=1$, therefore, lowers the efficiency of side-betting and the equilibrium consumption growth, and thus lowers the ex ante equilibrium interest rate. This is the second type effect of the public signal precision. When the public signal precision is extremely low, the first effect dominates the second type effect, vice versa. Eventually, the counterbalancing effects yield the bell-shaped ex ante equilibrium interest rate.

In order to see clearly the impact of the option and the public signal precision on the equilibrium interest rate, I compare the equilibrium interest rate in this model with the equilibrium interest rates in some benchmark models in Christensen and Qin (2012) in Figure 8.

\footnotetext{
${ }^{8}$ Note the equilibrium interest rate looks bell-shaped after the transformation $x=\ln \left(1+0.005 h_{\varepsilon}\right)$. The actual equilibrium is not exact bell-shaped, but still keep the property that the interest rate is first increasing, then decreasing, i.e., the equilibrium interest rate has only one maximum point.
} 


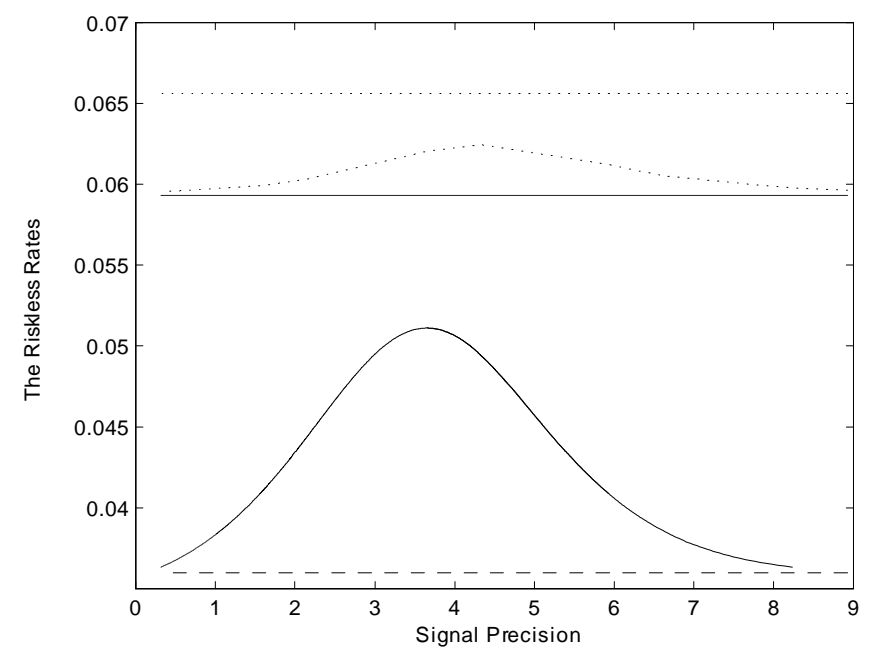

Figure 8. The Equilibrium Interest Rates in Different Models. The equilibrium interest rates in different models are plotted as functions of the public signal precision conditional on a certain level of the strike price. Note the bottom line of around 0.036 depicts the equilibrium interest rate in the benchmark model with only a zero-coupon bond and a stock. The above curve with a maximum point of around 0.052 indicates the equilibrium interest rate in the benchmark model in which the investors update their beliefs with imperfect public signal precision. The horizontal line of round 0.059 depicts the equilibrium interest rate in the benchmark model in which the investors speculate in the option markets and receiving no public signal or perfect public signal. The above curve with a maximum point of around 0.063 indicates the equilibrium interest rate in the model in which the investors update their beliefs with imperfect public signal precision and speculate in both the option markets and the underlying asset markets. The highest horizontal line depicts the equilibrium interest rate in the effectively complete market. The scale on the axis of the public signal precision is $x=\ln \left(1+0.005 h_{\varepsilon}\right)$. The parameters used when plotting the equilibrium interest rate as function of the public signal precision in Figure 8 are presented in Table 1, in addition to the prior variances $\sigma_{i}^{2}=0.0002, \sigma_{j}^{2}=0.0001$ and the strike price $K=0.01$.

As we can see from Figure 8, the bottom line is the equilibrium interest rate around 0.036 in the benchmark model in which the investors only trade in a zero-coupon bond and a stock. Note the increase of the equilibrium interest rate can be viewed as an analog of the gain from side-betting. Thus, this result illustrates the lowest efficiency of side-betting and benefit from the disagreement in the prior variance. When the investors can trade two rounds and update their beliefs with the imperfect public signal, the equilibrium interest rate is higher showing by the curve with a maximum point of around 0.052. This fact indicates that the imperfect public signal does facilitate side-betting when the investors heterogeneously 
update their beliefs. When the investors speculate with an option and receiving no public signal or perfect public signal, the equilibrium interest rate is even higher and increases to around 0.059, and the equilibrium interest rate increases again when the investors update their beliefs with imperfect public signal. This result indicates that the option and the public signal are capable of facilitating side-betting, leading to a higher growth in certainty equivalent and thus a higher equilibrium interest rate. Finally, the highest equilibrium interest rate is obtained when the investors trade with the derivative which payoffs a square of the dividend in the effectively complete market. This fact illustrates the option and the imperfect public signal still cannot make the investors take full advantage of the difference in beliefs, and the efficiency of side-betting is not as high as that in the effectively complete market.

Note first, Cuoco and He (1994) demonstrate the equilibrium with a stochastic weight in the representative agent utility is in general not Pareto efficient. Hence markets in Buraschi and Jiltsov (2006) are essentially incomplete, and they do not illustrate how much the option can help to improve the efficiency of side-betting. While, the model in this section shows that, the option and the imperfect public signal can facilitate side-betting, and increase the allocational efficiency of the markets to a better degree than that in some benchmark cases. Second, Buraschi and Jiltsov (2006) plot the asset pricing properties such as stock price and stock volatility as functions of the difference in the updated beliefs scaled by the signal volatility, hence the heterogeneous beliefs in their model carry the effect of the information system. However, I plot the asset pricing properties as functions of the different priors, thus the analysis in this paper probes the impact of the heterogeneity in beliefs and the public information quality separately.

\subsubsection{Ex Ante Equilibrium Risk Premium}

As in the previous section, I define the ex ante equilibrium risk premium on the risky underlying asset as $\varpi^{x a}=\ln \bar{m}^{h}-\ln \mathrm{E}^{Q}[d]$, where the weighted mean $\bar{m}^{h}$ and the riskadjusted expected dividend, $\mathrm{E}^{Q}[d]$, have the same definitions as in the previous section. To see the impact of the strike price and the public information quality, I plot the ex ante equilibrium risk premium as a function of the strike price and the public signal precision 
conditional on a certain level of heterogeneity in prior variance in Figure 9.
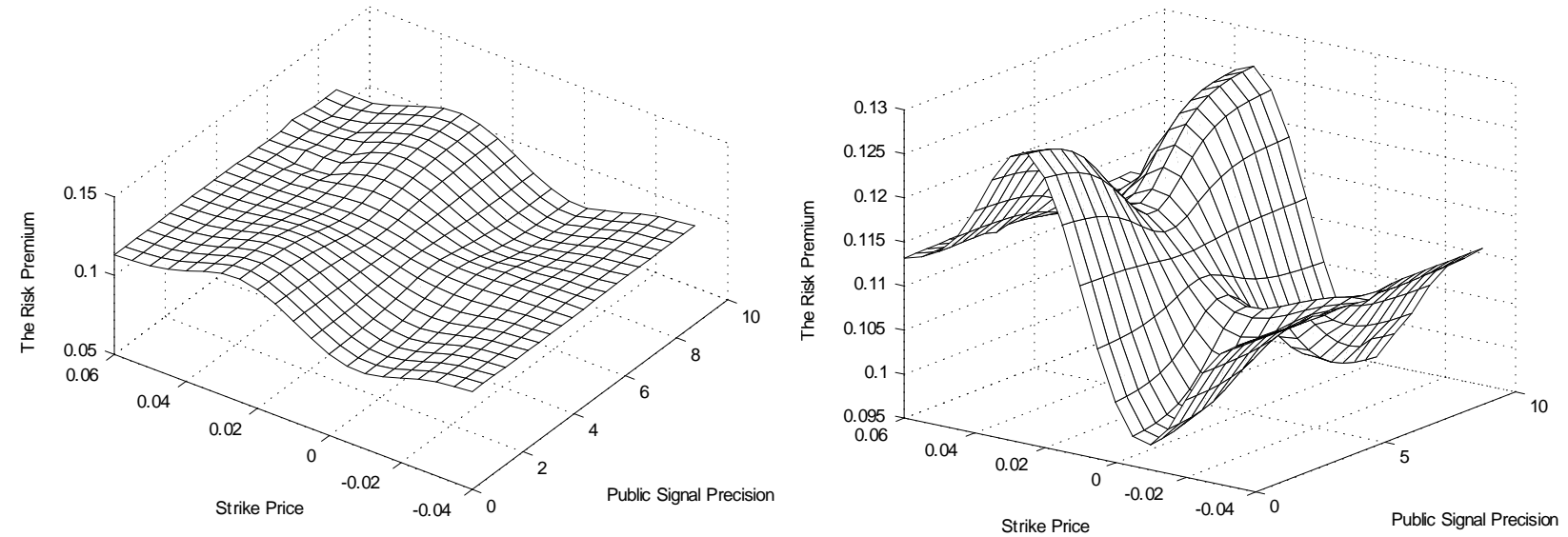

Figure 9. The Ex Ante Equilibrium Risk Premium. The ex ante equilibrium risk premium on the risky underlying asset is plotted as a function of the strike price and the public signal precision conditional on a certain level of heterogeneity in prior variance. The scale on the axis of public signal precision is $x=\ln \left(1+0.005 h_{\varepsilon}\right)$.

The ex ante risk premium surface in the panel is just like the inverted risk-adjusted expected dividend. With a fixed level of heterogeneous beliefs, when the strike price is much higher or much lower than the mean, the ex ante risk premium on the risky underlying asset converges to that in a benchmark case in which the investors trade only in a stock and a zero-coupon bond, which is independent of the public signal precision. However, with an intermediate strike price, the impact of the public signal precision on the ex ante equilibrium risk premium is nontrivial. This fact suggests that even though the strike price of option affects the ex ante risk premium on the risky underlying asset regardless of the presence of the public signal, the informativeness of the public information system affects the ex ante risk premium only via its relationship with the option.

Compare to the benchmark model in Christensen and Qin (2012), in which the ex ante risk premium is independent of the public signal precision, the ex ante risk premium in this paper is not aligned with investor welfare (as a function of the signal precision). The equilibrium interest rate and the investor welfare, however, are still perfectly aligned. This fact has an implication that it may be wise to be cautious in making policy statements about, for example, financial reporting regulation, based on empirical measures of equity premia (which are hard to measure reliably anyway).

Similar to the benchmark model in the previous sections, the intuition can be gained from the fact that the risk-adjusted expected dividend is the expected dividend plus the 
covariance of the marginal utility of consumption and the dividend scaled by the expected marginal utility of consumption. Actually, the surface of the covariance of the marginal utility of consumption and the dividend is similar to the inverted ex ante risk premium. Furthermore, the marginal utility of consumption is determined by the investors' portfolios. I plot the portfolios in financial markets as functions of the strike price and the public signal precision conditional on a certain level of heterogeneity in prior variance in Figure 10.
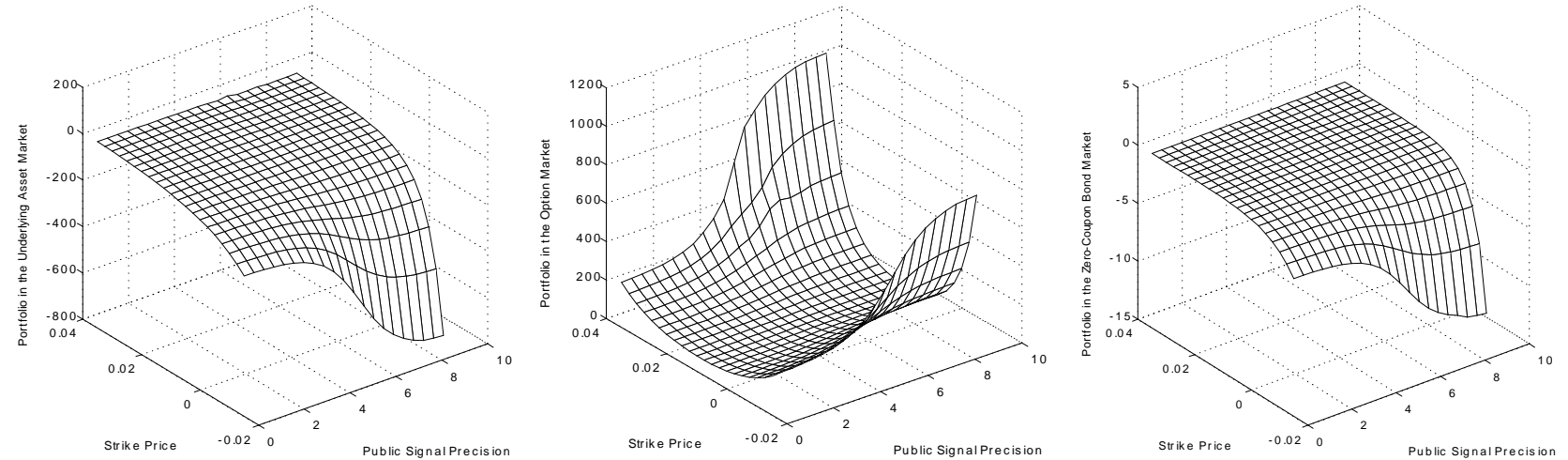

Figure 10. The Ex Ante Equilibrium Portfolios for Investor with Lower Prior Precision. The ex ante equilibrium portfolios for the investor with lower prior precision in the underlying asset markets, the option markets, the zero-coupon bond markets are plotted as functions of the strike price and the public signal precision conditional on a certain level of heterogeneity in prior variance in the left panel, middle panel, and right panel, respectively. The scale on the axis of public signal precision is $x=\ln \left(1+0.005 h_{\varepsilon}\right)$.

Conditional on a certain level of public signal precision, for the investor with lower prior precision, the portfolio in the option market is U-shaped. The intuition is similar to that in the benchmark models. Conditional on a certain level of strike price, the ex ante equilibrium demand of the option increases with the public signal precision. The intuition is that when the public signal precision increases, the variance of the posterior beliefs of the dividend decreases and, thus, the convexity of the option payoff at $t=1$ decreases. To gain more payoff convexity, the investors need to trade more in the option market at $t=0$. This result correspondingly increases the short positions in the underlying asset and the zero-coupon bond.

\subsubsection{Ex Ante Equilibrium Price of Risky Underlying Asset}

The underlying asset price is endogenized in the equilibrium as a function of the priors and the strike price. I plot the ex ante equilibrium underlying asset price as a function of the 
strike price and public signal precision conditional on a certain level of heterogeneity in prior variance in Figure 11.
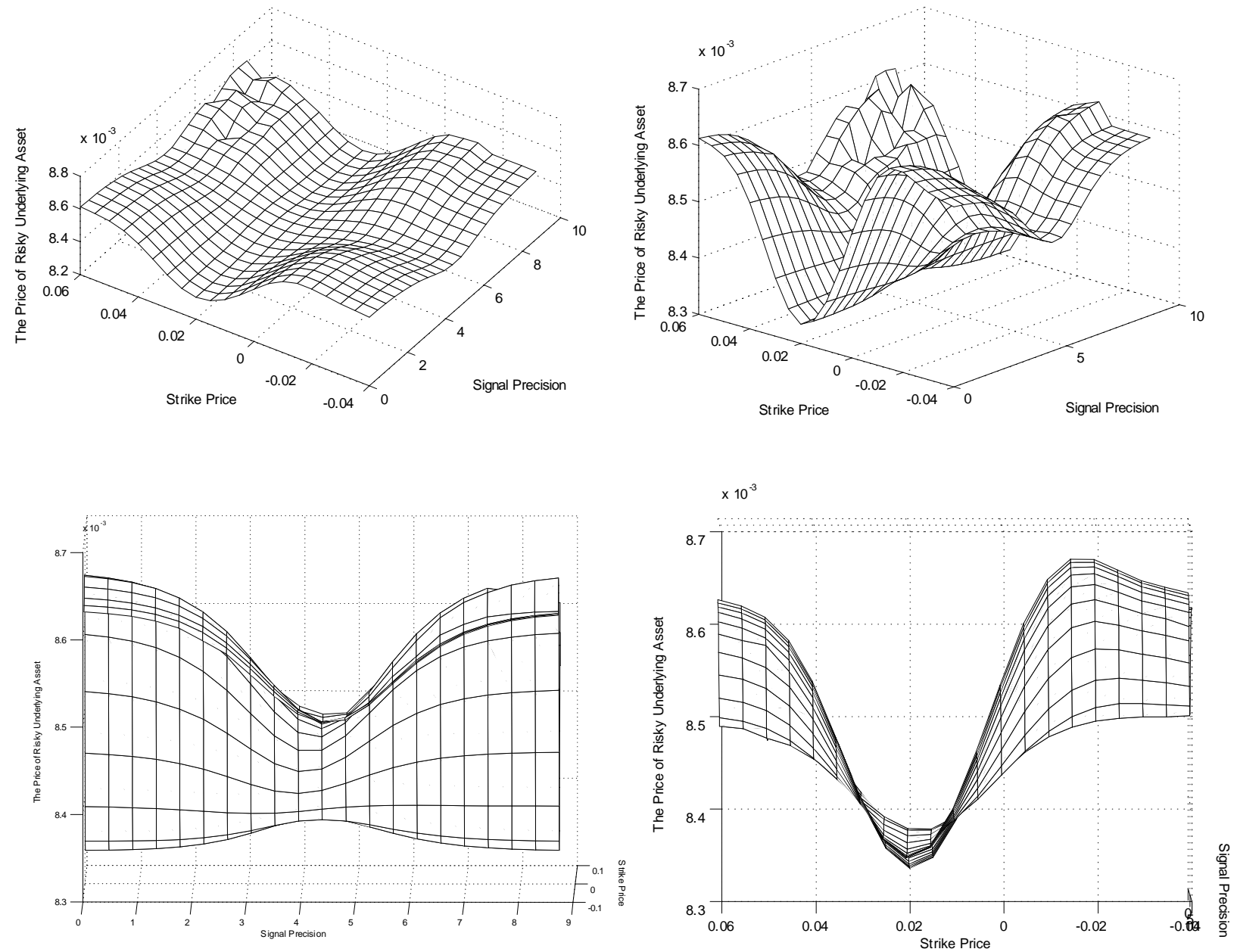

Figure 11. The Ex Ante Equilibrium Underlying Asset Price. The ex ante equilibrium underlying asset price is plotted as a function of the strike price and the public signal precision conditional on certain level of the heterogeneity in prior variance. The scale on the axis of the public signal precision is $x=\ln \left(1+0.005 h_{\varepsilon}\right)$.

The ex ante equilibrium underlying asset price is jointly determined by the public signal precision and the strike price through their effects on the ex ante equilibrium riskless discount factor and the risk-adjusted expected dividend. Similar to the results in the previous section, Figure 11 is a balanced result of Figure 7 and Figure 9. Moreover, in the benchmark model in which the investors update beliefs with imperfect public information and speculate in a stock and a zero-coupon bond, the lowest stock price is attainted at an intermediate public signal precision. Differently, after incorporating the option, the lowest price of the underlying asset 
is attained when there is no or perfect public signal, and at an intermediate strike price.

\subsubsection{Ex Ante Equilibrium Call Option Price}

The European call option price is endogenized in the equilibrium as a function of the priors and the strike price. I plot the ex ante equilibrium call option price as a function of strike price and public signal precision conditional on a certain level of heterogeneity in prior variance in Figure 12.

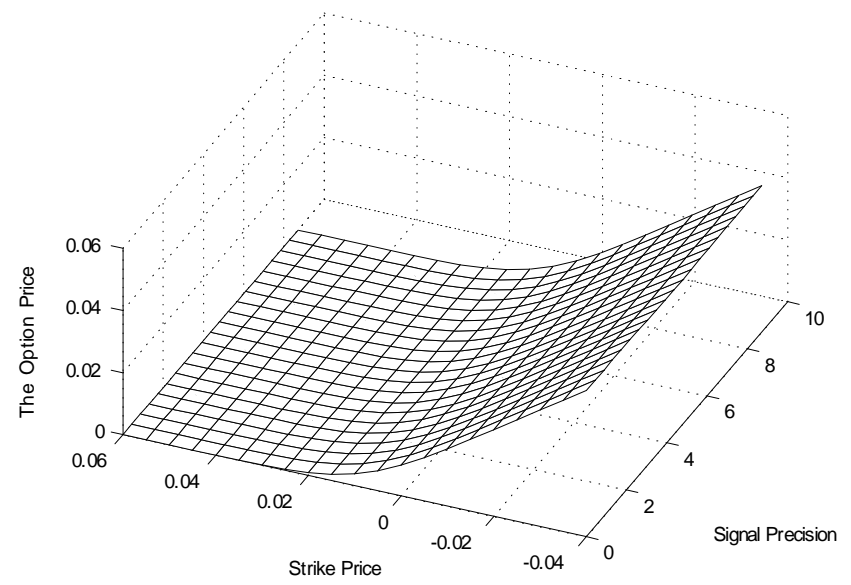

Figure 12. The Ex Ante Equilibrium Call Option Price. The ex ante equilibrium call option price is plotted as a function of the strike price and the public signal precision conditional on a certain level of the heterogeneity in prior variance. The scale on the axis of the public signal precision is $x=\ln \left(1+0.005 h_{\varepsilon}\right)$.

The ex ante equilibrium call option price is jointly determined by the public signal precision and the strike price through their effects on the ex ante equilibrium riskless discount factor and the risk-adjusted expected option payment. We can see from Figure 12 that the impact of the public signal precision on the ex ante equilibrium call option price is limited and hardly visible from the plot. The impact of the strike price is quite similar to that in the previous section: The value of the option decreases with the strike price, and converges to zero when the strike price increases to a very high level.

\subsubsection{Ex Ante Equilibrium Expected Utilities}

As mentioned before, the impact of the option and the public information system on individual utility depends on their individual endowments relative to their equilibrium portfolio 
at $t=0$. Therefore, the investors may not unanimously prefer this system over public information system. However, with equilibrium endowments of the market security, the ex ante equilibrium prices are independent of the investors' individual endowments, the investors do not trade at $t=0$ given these endowments, all the investors can benefit from the imperfect public signal and the option with an intermediate strike price.

\subsubsection{Case when Investors Update Beliefs and Speculate with Straddles}

As mentioned in Christensen and Qin (2012), in an incomplete market setting with heterogeneous beliefs about the risks on the underlying asset, straddles, i.e., long positions in both a call and a put option with the same strike price can play an important role to facilitate side-betting. Since straddle can resemble the payoff profile of the dividend derivative which pays off the square of dividend in the terminal date and effectively complete the market. The investors, who think the variance of the dividend is high, still can use Gamma strategy by trading straddle to achieve the convexity of its payoff while the investors, who think the variance is low, can take a short position to get a concave payoff profile. Thus the straddles have potential to exert an influence on the incomplete market settings with heterogeneous beliefs about the risks on the underlying assets. I derive the models when the investors speculate with straddle, receiving no public signal, imperfect public signal or perfect public signal, and solve for the equilibrium numerically. I find that the put option is able to facilitate side-betting, increase the growth in certainty equivalents and equilibrium interest rate. However, compare to the change of the level of equilibrium interest rate, the increase of the equilibrium interest rate which due to the incorporation of the put option is very small, and is hardly visible when plotting it. The same happens to other asset pricing properties such as the equilibrium underlying asset price, and the equilibrium risk premium. Hence, I do not repeat the figures in this section, but the derivations of the models are provided in Appendix B.

\section{Conclusion}

Under the assumptions of time-additive negative exponential investors and normally distributed dividend, this paper studies the relationship between the heterogeneous belief, the strike price and the public signal precision in the option markets without conditional on specific state of the economy. I demonstrate that the option market is important to facilitate financial market allocational efficiency when the investors hold heterogeneous beliefs. Moreover, the option market also makes the role of public signal precision more complicated and sophisticated. The public signal precision affects the ex ante risk premium on the risky 
underlying asset via this relationship with the option. When the investors do not speculate with the option, the public signal precision is independent of the ex ante risk premium. Combine with the right intermediate public signal precision and the right intermediate strike price, i.e., the right type of option, the highest allocational efficiency of the market can be attained, reflected by the unique maximum point of the $e x$ ante equilibrium interest rate surface.

In the effectively complete market, an additional asset of the right type eliminates the need for dynamic trading based on public signals and enables the investors to take full advantage of the heterogeneity in beliefs. Compare to that extreme case, I use option to facilitate side-betting and show that in this intermediate case, the public signal still has room to show its potential to facilitate improved dynamic trading opportunities and yields a more efficient market structure.

More trading rounds based on a sequence of the public signals may lead to more efficient side-betting based on the heterogeneous beliefs. To solve for such a multi-period ex ante equilibrium, the algorithms in Dumas and Lyasoff (2011) which solve for equilibrium recursively on an event tree can be helpful. Furthermore, as another extreme case, continuous trading may dynamically effectively complete the financial market with heterogeneous beliefs under the main assumptions in this paper. In other words, continuous trading may play a role as a compensation of long lived securities, but the market is essentially incomplete. I leave these cases for future research.

Another direction to extend this paper is to consider a CRRA-lognormal specification. The CARA-normal setting in this paper does buy some analytical tractability. However, more realistic preference and dividend distribution may come up with more empirically testable implications. Besides, the model can be generalized to a heterogeneous risk-aversion case. With identical prior precision, the least risk-averse investors are expected to tolerate risk and short options, while opposite speculative positions are taken by the most risk-averse investors.

\section{References}

Andersen, T. G., T. Bollerslev, F. X. Diebold, and C. Vega (2003). Micro effects of macro announcements: Real-time price discovery in foreign exchange. American Economic Review 93(1), 38-62.

Banerjee, S. and I. Kremer (2010). Disagreement and learning: Dynamic patterns of trade. Journal of Finance 65(4), 1269-1302. 
Black, F. and M. S. Scholes (1973). The pricing of options and corporate liabilities. Journal of Political Economy $81(3), 637-54$.

Brennan, M. (1998). The role of learning in dynamic portfolio decisions. European Finance Review 1, 295-306.

Brennan, M. J. and H. H. Cao (1996). Information, trade, and derivative securities. Review of Financial Studies 9(1), 163-208.

Brennan, M. J. and Y. Xia (2001). Stock price volatility and equity premium. Journal of Monetary Economics 47(2), 249-283.

Buraschi, A. and A. Jiltsov (2006). Model uncertainty and option markets with heterogeneous beliefs. Journal of Finance 61(6), 2841-2897.

Cao, H. H. and H. Ou-Yang (2009). Differences of opinion of public information and speculative trading in stocks and options. Review of Financial Studies 22(1), 299-335.

Chakravarty, S., H. Gulen, and S. Mayhew (2004). Informed trading in stock and option markets. Journal of Finance 59(3), 1235-1258.

Cherian, J. and W. Weng (1999). An empirical analysis of directional and volatility trading in options markets. Journal of Derivatives 7(2), 53-65.

Christensen, P. O. and G. Feltham (2003). Economics of accounting: Volume I - information in markets. Springer Science+Business Media, Inc. (Springer Series in Accounting Scholarship 1).

Christensen, P. O. and Z. Qin (2012). Heterogenous beliefs and information: Cost of capital, trade volume, and investor welfare. Working Paper, Aarhus University.

Cuoco, D. and H. He (1994). Dynamic aggregation and computation of equilibria in finitedimensional economies with incomplete financial markets. Research Program in Finance Working Papers, University of California at Berkeley (RPF-236).

David, A. (1997). Fluctuating confidence in stock markets: Implications for returns and volatility. Journal of Financial and Quantitative Analysis 32(04), 427-462.

David, A. (2008). Heterogeneous beliefs, speculation, and the equity premium. Journal of Finance 63(1), 41-83.

DeGroot, M. H. (1970). Optimal statistical decisions. New York: McGraw-Hill.

Detemple, J. and S. Murthy (1994). Intertemporal asset pricing with heterogeneous beliefs. Journal of Economic Theory 62(2), 294-320. 
Dumas, B. and A. Lyasoff (2011). Incomplete-market equilibria solved recursively on an event tree. Swiss Finance Institute Research Paper Series.

Easley, D., M. O'Hara, and P. Srinivas (1998). Option volume and stock prices: Evidence on where informed traders trade. Journal of Finance 53(2), 431-465.

Feltham, G. A. and J. Pae (2000). Analysis of the impact of accounting accruals on earnings uncertainty and response coefficients. Journal of Accounting, Auditing and Finance 15(3), 199-220.

Hakansson, N. H., J. G. Kunkel, and J. A. Ohlson (1982). Sufficient and necessary conditions for information to have social value in pure exchange. Journal of Finance 37 (5), 1169-81.

Heston, S. L. (1993). A closed-form solution for options with stochastic volatility with applications to bond and currency options. Review of Financial Studies 6(2), 327-43.

Hull, J. C. (2009). Options, futures, and other derivatives. Prentice-Hall, Englewood Cliffs, New Jersey.

Hull, J. C. and A. D. White (1987). The pricing of options on assets with stochastic volatilities. Journal of Finance 42(2), 281-300.

Li, T. (2008). Heterogeneous beliefs, option prices, and volatility smiles. Working Paper, City University of Hong Kong.

Lintner, J. (1969). The aggregation of investor's diverse judgments and preferences in purely competitive security markets. Journal of Financial and Quantitative Analysis 4(04), 347-400.

Liu, J. and J. Pan (2003). Dynamic derivative strategies. Journal of Financial Economics $69(3), 401-430$.

Milgrom, P. and N. Stokey (1982). Information, trade and common knowledge. Journal of Economic Theory 26(1), 17-27.

Morris, S. (1995). The common prior assumption in economic theory. Economics and Philosophy 11(02), 227-253.

Raiffa, H. and R. Schlaifer (1961). Applied statistical decision theory. Boston: Graduate School of Business Administration, Harvard University.

Richardson, S. A., R. G. Sloan, M. T. Soliman, and I. Tuna (2005). Accrual reliability, earnings persistence and stock prices. Journal of Accounting and Economics 39(3), 437-485. 
Vanden, J. M. (2004). Options trading and the capm. Review of Financial Studies 17(1), $207-238$.

Veronesi, P. (1999). Stock market overreaction to bad news in good times: A rational expectations equilibrium model. Review of Financial Studies 12(5), 975-1007.

Veronesi, P. (2000). How does information quality affect stock returns? Journal of Finance 55(2), 807-837.

Wilson, R. (1968). The theory of syndicates. Econometrica 36(1), 119-132.

\section{A Appendix: Proofs and Algorithms}

\section{A.1 Proof of Lemma 1}

Since the investor $i$ 's consumption at $t=2$ is

$$
c_{i 2}=\theta_{i 0} \max (d-K, 0)+x_{i 0} d+\gamma_{i 0},
$$

and let the probability density function of a Normal distribution $N\left(\mu, \sigma^{2}\right)$ be

$$
f\left(x ; \mu, \sigma^{2}\right)=\frac{1}{\sqrt{2 \pi \sigma^{2}}} \exp \left(-\frac{(x-\mu)^{2}}{2 \sigma^{2}}\right) .
$$

Hence, the $t=2$ expected utility for the investor $i$ is

$$
\begin{aligned}
& -\mathrm{E}\left[\exp \left[-r\left[\theta_{i 0} \max (d-K, 0)+x_{i 0} d+\gamma_{i 0}\right]\right]\right] \\
= & -\int_{-\infty}^{+\infty} \exp \left[-r\left[\theta_{i 0} \max (d-K, 0)+x_{i 0} d+\gamma_{i 0}\right]\right] f\left(x ; m_{i 0}, \sigma_{i 0}^{2}\right) d x \\
= & -\int_{-\infty}^{K} \exp \left[-r\left[x_{i 0} d+\gamma_{i 0}\right]\right] f\left(x ; m_{i 0}, \sigma_{i 0}^{2}\right) d x \\
& -\int_{K}^{+\infty} \exp \left[-r\left[\left(\theta_{i 0}+x_{i 0}\right) d-\theta_{i 0} K+\gamma_{i 0}\right]\right] f\left(x ; m_{i 0}, \sigma_{i 0}^{2}\right) d x \\
= & -\exp \left[-r\left[\gamma_{i 0}+m_{i 0} x_{i 0}-\frac{1}{2} r \sigma_{i 0}^{2} x_{i 0}^{2}\right]\right] \times \int_{-\infty}^{K} f\left(x ; m_{i 0}-r \sigma_{i 0}^{2} x_{i 0}, \sigma_{i 0}^{2}\right) d x \\
& -\exp \left[-r\left[\gamma_{i 0}-\theta_{i 0} K+m_{i 0}\left(\theta_{i 0}+x_{i 0}\right)-\frac{1}{2} r \sigma_{i 0}^{2}\left(\theta_{i 0}+x_{i 0}\right)^{2}\right]\right] \\
& \times \int_{K}^{+\infty} f\left(x ; m_{i 0}-r \sigma_{i 0}^{2}\left(\theta_{i 0}+x_{i 0}\right), \sigma_{i 0}^{2}\right) d x
\end{aligned}
$$




$$
\begin{aligned}
= & -\exp \left[-r\left[\gamma_{i 0}+m_{i 0} x_{i 0}-\frac{1}{2} r \sigma_{i 0}^{2} x_{i 0}^{2}\right]\right] \times \int_{-\infty}^{\frac{K-\left(m_{i 0}-r \sigma_{i 0}^{2} x_{i 0}\right)}{\sigma_{i 0}}} \phi(x) d x \\
& -\exp \left[-r\left[\gamma_{i 0}-\theta_{i 0} K+m_{i 0}\left(\theta_{i 0}+x_{i 0}\right)-\frac{1}{2} r \sigma_{i 0}^{2}\left(\theta_{i 0}+x_{i 0}\right)^{2}\right]\right] \\
& \times \int_{\frac{K-\left(m_{i 0}-r \sigma_{i 0}^{2}\left(\theta_{i 0}+x_{i 0}\right)\right)}{\sigma_{i 0}} \phi(x) d x}^{+\infty} \\
= & -\exp \left[-r\left[\gamma_{i 0}+m_{i 0} x_{i 0}-\frac{1}{2} r \sigma_{i 0}^{2} x_{i 0}^{2}\right]\right] \times \Phi\left(\frac{K-\left(m_{i 0}-r \sigma_{i 0}^{2} x_{i 0}\right)}{\sigma_{i 0}}\right) \\
& -\exp \left[-r\left[\gamma_{i 0}-\theta_{i 0} K+m_{i 0}\left(\theta_{i 0}+x_{i 0}\right)-\frac{1}{2} r \sigma_{i 0}^{2}\left(\theta_{i 0}+x_{i 0}\right)^{2}\right]\right] \\
& \times\left(1-\Phi\left(\frac{K-\left(m_{i 0}-r \sigma_{i 0}^{2}\left(\theta_{i 0}+x_{i 0}\right)\right)}{\sigma_{i 0}}\right)\right) \\
= & -\exp \left[-r\left[\gamma_{i 0}+m_{i 0} x_{i 0}-\frac{1}{2} r \sigma_{i 0}^{2} x_{i 0}^{2}\right]\right] \times\left\{\Phi\left(\frac{K-\left(m_{i 0}-r \sigma_{i 0}^{2} x_{i 0}\right)}{\sigma_{i 0}}\right)\right. \\
& -\exp \left[-r\left[-K+m_{i 0}-\frac{1}{2} r \sigma_{i 0}^{2} \theta_{i 0}-r \sigma_{i 0}^{2} x_{i 0}\right]\right] \\
& \times\left(1-\Phi\left(\frac{K-\left(m_{i 0}-r \sigma_{i 0}^{2}\left(\theta_{i 0}+x_{i 0}\right)\right)}{\sigma_{i 0}}\right)\right) \\
& \left(\frac{1}{2}\right)
\end{aligned}
$$

Therefore, the certainty equivalent of $t=2$ consumption for the investor $i$ is

$$
\begin{aligned}
\mathrm{CE}_{i 2}= & -\frac{1}{r} \ln \left(-U_{i 2}\left(\theta_{i 0}, x_{i 0}, \gamma_{i 0} \mid m_{i 0}, \sigma_{i 0}^{2}\right)\right) \\
= & \gamma_{i 0}+m_{i 0} x_{i 0}-\frac{1}{2} r \sigma_{i 0}^{2} x_{i 0}^{2}-\frac{1}{r} \ln \left\{\Phi\left(\frac{K-\left(m_{i 0}-r \sigma_{i 0}^{2} x_{i 0}\right)}{\sigma_{i 0}}\right)\right. \\
& +\exp \left[-r \theta_{i 0}\left[-K+m_{i 0}-\frac{1}{2} r \sigma_{i 0}^{2} \theta_{i 0}-r \sigma_{i 0}^{2} x_{i 0}\right]\right] \\
& \left.\times\left(1-\Phi\left(\frac{K-\left(m_{i 0}-r \sigma_{i 0}^{2}\left(\theta_{i 0}+x_{i 0}\right)\right)}{\sigma_{i 0}}\right)\right)\right\} .
\end{aligned}
$$

This completes the proof. 


\section{A.2 Calculate the First Derivatives in Model 3.1 and 3.2 and Derivation of Equilibrium Price of Underlying Asset}

This section provides the calculation of the first derivatives in first-order condition. Let

$$
\begin{aligned}
a_{i} & =\frac{K-\left(m_{i 0}-r \sigma_{i 0}^{2} x_{i 0}\right)}{\sigma_{i 0}}, \\
b_{i} & =\frac{K-\left(m_{i 0}-r \sigma_{i 0}^{2}\left(\theta_{i 0}+x_{i 0}\right)\right)}{\sigma_{i 0}} \\
c_{i} & =\exp \left[-r \theta_{i 0}\left[-K+m_{i 0}-\frac{1}{2} r \sigma_{i 0}^{2} \theta_{i 0}-r \sigma_{i 0}^{2} x_{i 0}\right]\right]
\end{aligned}
$$

therefore,

$$
f_{i}\left(x_{i 0}, \theta_{i 0}\right)=-\frac{1}{r} \ln \left\{\psi_{i}\right\}
$$

where $\psi_{i} \equiv \Phi\left(a_{i}\right)+c_{i} \times\left(1-\Phi\left(b_{i}\right)\right)$, and $\Phi(\cdot)$ is the cumulative distribution function of the standard normal distribution. Hence,

$$
\begin{aligned}
\frac{\partial f_{i}\left(x_{i 0}, \theta_{i 0}\right)}{\partial x_{i 0}} & =-\frac{\phi\left(a_{i}\right) \sigma_{i 0}-\phi\left(b_{i}\right) \sigma_{i 0} c_{i}+(1-\Phi(b)) c_{i} r \sigma_{i 0}^{2} \theta_{i 0}}{\Phi\left(a_{i}\right)+\left(1-\Phi\left(b_{i}\right)\right) c_{i}} \\
\frac{\partial f_{i}\left(x_{i 0}, \theta_{i 0}\right)}{\partial \theta_{i 0}} & =\frac{\phi\left(b_{i}\right) \sigma_{i 0} c_{i}+\left(1-\Phi\left(b_{i}\right)\right)\left(m_{i 0}-K-r \sigma_{i 0}^{2} \theta_{i 0}-r \sigma_{i 0}^{2} x_{i 0}\right) c_{i}}{\Phi\left(a_{i}\right)+\left(1-\Phi\left(b_{i}\right)\right) c_{i}}
\end{aligned}
$$

where $\phi(x)$ denotes the standard normal probability density function, hence

$$
\phi(x)=\frac{1}{\sqrt{2 \pi}} \exp \left(-\frac{x^{2}}{2}\right) .
$$

Now I derive the price of the underlying asset as the product of equilibrium riskless discount factor and the risk-adjusted expected dividend. The investor $i$ 's first-order condition gives

$$
\begin{gathered}
\frac{\partial\left(-\exp \left(-r \mathrm{CE}_{i 0}\right)-\exp (-\delta) \exp \left(-r \mathrm{CE}_{i 2}\right)\right)}{\partial x_{i 0}}=0 \Leftrightarrow \\
-r \exp \left(-r \mathrm{CE}_{i 0}\right) p_{0}(\eta)-\frac{\partial\left(\exp (-\delta) \exp \left(-r \mathrm{CE}_{i 2}\right)\right)}{\partial x_{i 0}}=0 \Leftrightarrow \\
r p_{0}(\eta) \exp \left(-r \mathrm{CE}_{i 0}\right)=-\frac{\partial\left(\exp (-\delta) \exp \left(-r \mathrm{CE}_{i 2}\right)\right)}{\partial x_{i 0}} \Leftrightarrow \\
\ln \left(r p_{0}(\eta)\right)-r \mathrm{CE}_{i 0}=\ln \left(-\frac{\partial\left(\exp (-\delta) \exp \left(-r \mathrm{CE}_{i 2}\right)\right)}{\partial x_{i 0}}\right)
\end{gathered}
$$


and sum over $i$, yields

$$
\begin{aligned}
& I \ln \left(r p_{0}(\eta)\right)-r\left(\mathrm{CE}_{i 0}+\mathrm{CE}_{j 0}\right)=\sum_{i=1}^{I} \ln \left(-\frac{\partial\left(\exp (-\delta) \exp \left(-r \mathrm{CE}_{i 2}\right)\right)}{\partial x_{i 0}}\right) \Leftrightarrow \\
& I \ln \left(r p_{0}(\eta)\right)-r d_{0} Z=\ln \left(\prod_{i=1}^{I} \frac{-\partial\left(\exp (-\delta) \exp \left(-r \mathrm{CE}_{i 2}\right)\right)}{\partial x_{i 0}}\right) \Leftrightarrow \\
& \ln \left(r p_{0}(\eta)\right)=\frac{1}{I} r d_{0} Z+\frac{1}{I} \ln \left(\prod_{i=1}^{I} \frac{-\partial\left(\exp (-\delta) \exp \left(-r \mathrm{CE}_{i 2}\right)\right)}{\partial x_{i 0}}\right) \Leftrightarrow \\
& p_{0}(\eta)=\frac{1}{r}\left(\prod_{i=1}^{I} \frac{-\partial\left(\exp (-\delta) \exp \left(-r \mathrm{CE}_{i 2}\right)\right)}{\partial x_{i 0}}\right)^{\frac{1}{I}} \exp \left[\frac{1}{I} r d_{0} Z\right] \\
& =\frac{1}{r}\left(\prod_{i=1}^{I} \frac{-\partial\left(\exp (-\delta) \exp \left(-r \mathrm{CE}_{i 2}\right)\right)}{\partial x_{i 0}}\right)^{\frac{1}{I}} \exp \left[\frac{1}{I} r \sum_{i=1}^{I} \mathrm{CE}_{i 0}\right] \\
& =\frac{1}{r}\left(\prod_{i=1}^{I} r\left(m_{i 0}-r \sigma_{i 0}^{2} x_{i 0}+\frac{\partial f_{i}\left(x_{i 0}, \theta_{i 0}\right)}{\partial x_{i 0}}\right)\right)^{\frac{1}{I}} \exp \left(-\delta-\frac{r}{I} \sum_{i=1}^{I} \mathrm{CE}_{i 2}\right) \exp \left[\frac{r}{I} \sum_{i=1}^{I} \mathrm{CE}_{i 0}\right] \\
& =\frac{1}{r}\left(\prod_{i=1}^{I} r\left(m_{i 0}-r \sigma_{i 0}^{2} x_{i 0}+\frac{\partial f_{i}\left(x_{i 0}, \theta_{i 0}\right)}{\partial x_{i 0}}\right)\right)^{\frac{1}{I}} \exp \left(-\delta-\frac{r}{I} \sum_{i=1}^{I} \mathrm{CE}_{i 2}+\frac{r}{I} \sum_{i=1}^{I} \mathrm{CE}_{i 0}\right) \\
& =\beta_{0}\left(\prod_{i=1}^{I}\left(m_{i 0}-r \sigma_{i 0}^{2} x_{i 0}+\frac{\partial f_{i}\left(x_{i 0}, \theta_{i 0}\right)}{\partial x_{i 0}}\right)\right)^{\frac{1}{I}} \text {. }
\end{aligned}
$$

\section{A.3 Algorithm to Compute the Ex Ante Expected Utility at $t=2$}

The expectation of the utility for the investor $i$ at $t=2$ can be expressed as

$$
\begin{aligned}
& -\mathrm{E}\left[\exp \left[-r \mathrm{CE}_{i 2}\left(x_{i 0}, \theta_{i 0}, \gamma_{i 0}, \beta_{0}, p_{0}, \pi_{0}, x_{i 1}(y), \theta_{i 1}(y), p_{1}(y), \pi_{1}(y) \mid \mathcal{F}_{1}\right)\right]\right] \\
= & -\frac{1}{\sqrt{2 \pi\left(\sigma_{i}^{2}+\sigma_{\varepsilon}^{2}\right)}} \int_{-\infty}^{+\infty} \exp \left[-r \mathrm{CE}_{i 2}(y)\right] \exp \left(-\frac{\left(m_{i}-y\right)^{2}}{2\left(\sigma_{i}^{2}+\sigma_{\varepsilon}^{2}\right)}\right) d y .
\end{aligned}
$$


The integral over infinite interval can then be evaluated by ordinary integration methods:

$$
\int_{-H}^{H} f(t) d t \approx \frac{2 H}{n}\left(\frac{f(-H)+f(H)}{2}+\sum_{k=1}^{n-1} f\left(a+k \frac{2 H}{n}\right)\right),
$$

when $H \rightarrow \infty$ and $n \rightarrow \infty, \int_{-H}^{H} f(t) d t \rightarrow \int_{-\infty}^{\infty} f(t) d t$.

Note that for each public signal $y$, a corresponding ex post equilibrium can be solved for and yield the ex post equilibrium portfolios $\theta_{i 1}, \theta_{j 1}, x_{i 1}, x_{j 1}$, and the ex post prices, $p_{1}(y)$ and $\pi_{1}(y)$. Sum up $-\frac{1}{\sqrt{2 \pi\left(\sigma_{i}^{2}+\sigma_{\varepsilon}^{2}\right)}} \exp \left[-r \mathrm{CE}_{i 2}(y)\right] \exp \left(-\frac{\left(m_{i}-y\right)^{2}}{2\left(\sigma_{i}^{2}+\sigma_{\varepsilon}^{2}\right)}\right)$ over all the public signal $y$ yields the expectation.

Also note that the public signal $y \sim N\left(m_{i}, \sigma_{i}^{2}+\sigma_{\varepsilon}^{2}\right)$, hence, let $u=\frac{y-m_{i}}{\sqrt{\sigma_{i}^{2}+\sigma_{\varepsilon}^{2}}}$, then $u \sim$ $N(0,1)$. This transformation can make the probability density of the normal distribution be independent of the public signal precision, and bring some conveniences when programming.

\section{A.4 Algorithm to Solve Nonlinear Equations in Ex Post and Ex Ante Equilibriums}

Denote the system of the nonlinear equations as $G(x)$, where $x$ is a vector and $G(x)$ is a function that returns a vector value. I use nonlinear least-squares algorithms to find $x$ that is a local minimizer to a function that is a sum of squares, i.e.,

$$
\min _{x}\|G(x)\|_{2}^{2}=\min _{x} \sum_{i} \alpha_{i} G_{i}^{2}(x)
$$

Specifically, in this paper, I have some manipulations corresponding to the properties of the equations. First, I set a larger weight $\alpha_{i}$ to the first-order condition equations than the market clearing equations, and the weights depend on the value of the parameters. This is because the first-order condition equations are more nonlinear and difficult to converge properly when iterating. Second, since the coefficients of the portfolio unknowns are very small when the public signal precision is comparatively low, the value of the equations are not sensitive to the change of the value of the portfolios and thus the portfolios unknowns are more difficult to converge. To solve this problem, first time the portfolio unknowns by a large constant, $N$, to make the value of the portfolios more influential. After solving the equations, I time the same constant, $N$, again to the solutions of the portfolios and obtain better converged value of portfolios. The value of the constant, $N$, depends on the value of parameters. With the parameters used in this paper, $N \in[1,10000]$, can be chosen regarding 
difference equilibriums.

Regarding the nonlinear least-squares algorithms, I first use the Gauss-Newton method. The Gauss-Newton method is more efficient when searching for a good starting point, but not robust to converge to a solution. If the solution is not well converged, then I turn to the Levenberg-Maquardt method. The robustness of the Levenberg-Marquardt method compensates for its occasional poor efficiency. Above algorithms can be implemented by employing the function fsolve in MATLAB. Set parameters 'LargeScale','off','NonlEqnAlgorithm', 'gn' when using the Levenberg-Marquardt method. Robustness measures are included in the method.

For the iteration formulas refer to, e.g.,

\section{http://www.mathworks.com/help/toolbox/optim/ug/brnoybu.html\#brnoyco}

The residuals can be very small when solving the equations with the parameters used in this paper. It is possible to obtain the value of $\|G(x)\|_{2}^{2}<10^{-20},\left|G_{i}(x)\right|<10^{-10}$, for almost all the ex post and ex ante equilibriums. Hence the solutions converge properly.

To reduce the computing time, in a two-investor model, I rearrange the equilibrium equations at $t=1$ and $t=0$. Note the equations are partly nonlinear, for instance, the market clearing condition is linear, and the asset price in the first order condition is also linear. Hence in the ex post equilibriums (see section 3.2.1), I can rewrite the equilibrium equations at $t=1$ into nonlinear equations with only two unknowns, i.e., the portfolios in the risky asset markets of one investor, $x_{i 1}, \theta_{i 1}$,

$$
\begin{aligned}
m_{i 1}-r \sigma_{i 1}^{2} x_{i 1}+\frac{\partial f_{i}\left(x_{i 1}, \theta_{i 1}\right)}{\partial x_{i 1}} & =m_{j 1}-r \sigma_{j 1}^{2}\left(Z-x_{i 1}\right)+\frac{\partial f_{j}\left(\left(Z-x_{i 1}\right),-\theta_{i 1}\right)}{\partial x_{j 1}} \\
\frac{\partial f_{i}\left(x_{i 1}, \theta_{i 1}\right)}{\partial x_{i 1}} & =\frac{\partial f_{j}\left(\left(Z-x_{i 1}\right),-\theta_{i 1}\right)}{\partial x_{j 1}} .
\end{aligned}
$$

After solving the two-unknown equations and obtaining the value of the portfolios, one can use the following linear relationships to calculate the values of the other unknowns:

$$
\begin{aligned}
x_{j 1} & =Z-x_{i 1} \\
\theta_{j 1} & =-\theta_{i 1} \\
p_{1} & =m_{i 1}-r \sigma_{i 1}^{2} x_{i 1}+\frac{\partial f_{i}\left(x_{i 1}, \theta_{i 1}\right)}{\partial x_{i 1}} \\
\pi_{1} & =\frac{\partial f_{i}\left(x_{i 1}, \theta_{i 1}\right)}{\partial x_{i 1}}
\end{aligned}
$$

Similarly, the nonlinear equations at $t=0$ can be written into nonlinear equations with only three unknowns, i.e., the portfolios in the risky and riskless asset markets of one 
investor. With fewer unknowns in the nonlinear equations, the computing time reduces greatly, however, the accuracy of the solutions may also be affected slightly.

There are some other practical issues worth mentioning. When I solve for the equilibrium at $t=1$, I set the value of the public signal $y$ vary widely, since $y$ is normally distributed. For some value of the public signal $y$ and the public signal precision $h_{\varepsilon}$, the value of the cumulative distribution function of the standard normal distribution, $\Phi(\cdot)$ can be very close to 1 or 0 during the iteration. The computer may have difficulty to tell if it is $1 / 0$ or a number very close to $1 / 0$ due to the limited computing precision. If this situation happens, the solutions may not converge properly. To solve this problem, I set a threshold $q=10^{-10}$, when $\Phi(\cdot)<q$, let $\Phi(\cdot)=0$, then according to the expression of $\partial f_{i}\left(x_{i 1}(y), \theta_{i 1}(y)\right)$ in Eq. (A1), yields

$$
f_{i}\left(x_{i 1}(y), \theta_{i 1}(y)\right)=-\frac{1}{r} \ln c_{i}=\theta_{i 1}(y)\left[-K+m_{i 1}-\frac{1}{2} r \sigma_{i 1}^{2} \theta_{i 1}(y)-r \sigma_{i 1}^{2} x_{i 1}(y)\right] .
$$

When $1-\Phi(\cdot)<q$, let $\Phi(\cdot)=1$, and thus $f_{i}\left(x_{i 1}(y), \theta_{i 1}(y)\right)=0$. Hence, at $t=1$, the function $f_{i}\left(x_{i 1}(y), \theta_{i 1}(y)\right)$ follows different kinds of form conditional on the value of $\Phi(\cdot)$ in the iteration. Regarding each form, new equations need to be solved. This classification can enhance the accuracy of the solution and reduce computing time considerably.

\section{B Derivation of the Model when Investors Update Be- liefs and Speculate with Straddles}

As indicated in the introduction, in incomplete market settings with heterogeneous beliefs about the risks on the underlying asset, the straddles, i.e., long positions in both a call and a put option with the same strike price can play an important role to facilitate side-betting.

Based on the model in sections 3.1 and 3.2, I now add an additional European put option in zero net supply with payoff, $\max (K-d, 0)$, at $t=2$, and the prices $v_{0}(\eta)$ and $v_{1}(y)$ at $t=0$ and $t=1$, respectively. The investors have endowments $\bar{\xi}_{i}$ of this asset at $t=0$, and let $\xi_{i 0}$ it be the units of the put option held after trading at date $t$ satisfying the market clearing conditions

$$
\sum_{i=1}^{I} \bar{\xi}_{i t}=\sum_{i=1}^{I} \xi_{i t}=0, t=0,1
$$




\section{B.1 Benchmark Case when Investors Speculate with Straddles Receiving No or Perfect Public Signal}

I first derive a benchmark model in which the investors receive no public signal or perfect public signal at $t=1$, hence the model is equivalent to a single period model.

\section{B.1.1 Equilibrium in a Single Period Economy}

From the perspective of $t=0$, the date $t=2$ consumption for the investor $i$ is

$$
c_{i 2}=\theta_{i 0} \max (d-K, 0)+\xi_{i 0} \max (K-d, 0)+x_{i 0} d+\gamma_{i 0} .
$$

Given the period-specific negative exponential utility, the investor $i$ s' $t=0$ certainty equivalent of $t=2$ consumption, receiving no or perfect public information at $t=1$, $\mathrm{CE}_{i 2}\left(\xi_{i 0}, \theta_{i 0}, x_{i 0}, \gamma_{i 0}\right)$ can be calculated according to Lemma 2.

Lemma 2 Assume the investors receive no or perfect public information at $t=1$, given the portfolios in the underlying asset markets, the call option markets, the put option markets, and the zero-coupon bond markets at $t=0$, the investor $i$ 's certainty equivalent of $t=2$ consumption is

$$
\mathrm{CE}_{i 2}\left(\xi_{i 0}, \theta_{i 0}, x_{i 0}, \gamma_{i 0}\right)=\gamma_{i 0}+m_{i 0} x_{i 0}-\frac{1}{2} r \sigma_{i 0}^{2} x_{i 0}^{2}+g_{i}\left(x_{i 0}, \theta_{i 0}, \xi_{i 0}\right)
$$

where

$$
\begin{aligned}
g_{i}\left(x_{i 0}, \theta_{i 0}, \xi_{i 0}\right)= & -\frac{1}{r} \ln \left\{\exp \left[-r \xi_{i 0}\left[K-m_{i 0}-\frac{1}{2} r \sigma_{i 0}^{2} \xi_{i 0}+r \sigma_{i 0}^{2} x_{i 0}\right]\right]\right. \\
& \times \Phi\left(\frac{K-\left(m_{i 0}-r \sigma_{i 0}^{2}\left(x_{i 0}-\xi_{i 0}\right)\right)}{\sigma_{i 0}}\right) \\
& +\exp \left[-r \theta_{i 0}\left[-K+m_{i 0}-\frac{1}{2} r \sigma_{i 0}^{2} \theta_{i 0}-r \sigma_{i 0}^{2} x_{i 0}\right]\right] \\
& \left.\times\left(1-\Phi\left(\frac{K-\left(m_{i 0}-r \sigma_{i 0}^{2}\left(\theta_{i 0}+x_{i 0}\right)\right)}{\sigma_{i 0}}\right)\right)\right\},
\end{aligned}
$$

and $\Phi(\cdot)$ is the cumulative distribution function of the standard normal distribution.

Proof: See Appendix B3.

The investors' $t=0$ certainty equivalent equals to the date $t=0$ consumption, i.e.,

$$
\mathrm{CE}_{i 0}=c_{i 2}=d_{0} \bar{z}_{i}+\left(\bar{\xi}_{i 0}-\xi_{i 0}\right) v_{0}(\eta)+\left(\bar{\theta}_{i}-\theta_{i 0}\right) \pi_{0}(\eta)+\left(\bar{\gamma}_{i}-\gamma_{i 0}\right) \beta_{0}+\left(\bar{z}_{i}-x_{i 0}\right) p_{0}(\eta),
$$


the investor $i$ 's decision problem at $t=0$ can be stated as follows

$$
\max _{\xi_{i 0}, \theta_{i 0}, \gamma_{i 0}, x_{i 0}}-\exp \left(-r \mathrm{CE}_{i 0}\right)-\exp (-\delta) \exp \left(-r \mathrm{CE}_{i 2}\right)
$$

To solve for the equilibrium, I first solve the investor $i$ 's optimal portfolio choice problem,

$$
\begin{aligned}
& \frac{\partial\left(-\exp \left(-r \mathrm{CE}_{i 0}\right)-\exp (-\delta) \exp \left(-r \mathrm{CE}_{i 2}\right)\right)}{\partial \xi_{i 0}}=0 \\
& \frac{\partial\left(-\exp \left(-r \mathrm{CE}_{i 0}\right)-\exp (-\delta) \exp \left(-r \mathrm{CE}_{i 2}\right)\right)}{\partial x_{i 0}}=0 \\
& \frac{\partial\left(-\exp \left(-r \mathrm{CE}_{i 0}\right)-\exp (-\delta) \exp \left(-r \mathrm{CE}_{i 2}\right)\right)}{\partial \theta_{i 0}}=0 \\
& \frac{\partial\left(-\exp \left(-r \mathrm{CE}_{i 0}\right)-\exp (-\delta) \exp \left(-r \mathrm{CE}_{i 2}\right)\right)}{\partial \gamma_{i 0}}=0 .
\end{aligned}
$$

Note more details of the calculation of the first derivatives in the first-order condition are provided in Appendix B4. Then the equilibrium portfolios and the prices are the implicit solutions of the system of equations which arise from the first-order conditions for the portfolio of each asset, and the market clearing condition for each asset, i.e.,

$$
\sum_{i=1}^{I} \gamma_{i 0}=0, \quad \sum_{i=1}^{I} \xi_{i 0}=0, \quad \sum_{i=1}^{I} \theta_{i 0}=0, \text { and } \sum_{i=1}^{I} x_{i 0}=Z
$$

\section{B.2 Case when Investors Update Beliefs with Imperfect Public Signal and Speculate with Straddles}

I now derive a dynamic trading model in which the investors trade in both call and put option markets and update their beliefs at $t=1$ with imperfect public information.

\section{B.2.1 Equilibrium Prices at $t=1$}

I first derive the ex post equilibrium at $t=2$ conditional on the posterior beliefs. From the perspective of $t=1$, date $t=2$ consumption for the investor $i$ is

$$
c_{i 2}=\theta_{i 1}(y) \max (d-K, 0)+\xi_{i 1}(y) \max (K-d, 0)+x_{i 1}(y) d+\gamma_{i 1}(y) .
$$

Given the period-specific negative exponential utility, the investor $i$ maximizes his certainty equivalent of $t=2$ consumption (conditional on the public information at $t=1$ ), 
subject to his budget constraint, i.e.,

$$
\begin{aligned}
& \max _{\xi_{i 1}(y), \theta_{i 1}(y), x_{i 1}(y), \gamma_{i 1}(y)} \operatorname{CE}_{i 2}\left(\xi_{i 1}(y), \theta_{i 1}(y), x_{i 1}(y), \gamma_{i 1}(y) \mid m_{i 1}, \sigma_{i 1}^{2}\right) \\
& \text { subject to } \beta_{1} \gamma_{i 1}(y)+p_{1}(y) x_{i 1}(y)+\pi_{1}(y) \theta_{i 1}(y)+v_{1}(y) \xi_{i 1}(y) \\
\leq & \beta_{1} \gamma_{i 0}+p_{1}(y) x_{i 0}+\pi_{1}(y) \theta_{i 0}+v_{1}(y) \xi_{i 0}
\end{aligned}
$$

where $\mathrm{CE}_{i 2}\left(\xi_{i 1}(y), \theta_{i 1}(y), x_{i 1}(y), \gamma_{i 1}(y) \mid m_{i 1}, \sigma_{i 1}^{2}\right)$ can be obtained by Lemma 2 .

The ex post certainty equivalent of $t=2$ consumption of the investor $i$ (conditional on the public information at $t=1$ ) is

$$
\begin{aligned}
& \mathrm{CE}_{i 2}\left(\xi_{i 1}(y), \theta_{i 1}(y), x_{i 1}(y), \gamma_{i 1}(y) \mid m_{i 1}, \sigma_{i 1}^{2}\right) \\
= & \gamma_{i 1}(y)+m_{i 1} x_{i 1}(y)-\frac{1}{2} r \sigma_{i 1}^{2} x_{i 1}^{2}(y)+g_{i}\left(x_{i 1}(y), \xi_{i 1}(y), \theta_{i 1}(y)\right),
\end{aligned}
$$

where

$$
\begin{aligned}
g_{i}\left(\xi_{i 1}, x_{i 1}, \theta_{i 1}\right)= & -\frac{1}{r} \ln \left\{\exp \left[-r \xi_{i 1}(y)\left[K-m_{i 1}-\frac{1}{2} r \sigma_{i 1}^{2} \xi_{i 1}(y)+r \sigma_{i 1}^{2} x_{i 1}(y)\right]\right]\right. \\
& \times \Phi\left(\frac{K-\left(m_{i 1}-r \sigma_{i 1}^{2}\left(x_{i 1}(y)-\xi_{i 1}(y)\right)\right)}{\sigma_{i 1}}\right) \\
& +\exp \left[-r \theta_{i 1}(y)\left[-K+m_{i 1}-\frac{1}{2} r \sigma_{i 1}^{2} \theta_{i 1}(y)-r \sigma_{i 1}^{2} x_{i 1}(y)\right]\right] \\
& \left.\times\left(1-\Phi\left(\frac{K-\left(m_{i 1}-r \sigma_{i 1}^{2}\left(\theta_{i 1}(y)+x_{i 1}(y)\right)\right)}{\sigma_{i 1}}\right)\right)\right\} .
\end{aligned}
$$

To solve the investor $i$ 's optimal portfolio choice problem, let the Lagrangian be

$$
\begin{aligned}
\overline{\mathcal{L}}_{i}= & \gamma_{i 1}(y)+m_{i 1} x_{i 1}(y)-\frac{1}{2} r \sigma_{i 1}^{2} x_{i 1}^{2}(y)+g_{i}\left(\xi_{i 1}(y), x_{i 1}(y), \theta_{i 1}(y)\right) \\
& +\lambda\left(\begin{array}{c}
\beta_{1}\left(\gamma_{i 1}(y)-\gamma_{i 0}\right)+p_{1}(y)\left(x_{i 1}(y)-x_{i 0}\right) \\
+\pi_{1}(y)\left(\theta_{i 1}(y)-\theta_{i 0}\right)+v_{1}(y)\left(\xi_{i 1}(y)-\xi_{i 0}\right)
\end{array}\right) .
\end{aligned}
$$

Assume $\beta_{1}=1$ as the numeraire in the model, thus from

$$
\frac{\partial \overline{\mathcal{L}}_{i}}{\partial \gamma_{i 1}}=1+\lambda \beta_{1}=0
$$


yields $\lambda=-1$, hence

$$
\begin{aligned}
\overline{\mathcal{L}}_{i}= & \gamma_{i 1}(y)+m_{i 1} x_{i 1}(y)-\frac{1}{2} r \sigma_{i 1}^{2} x_{i 1}^{2}(y)+g_{i}\left(x_{i 1}(y), \theta_{i 1}(y), \xi_{i 1}(y)\right) \\
& -\left(\begin{array}{c}
\gamma_{i 1}(y)-\gamma_{i 0}+p_{1}(y)\left(x_{i 1}(y)-x_{i 0}\right) \\
+\pi_{1}(y)\left(\theta_{i 1}(y)-\theta_{i 0}\right)+v_{1}(y)\left(\xi_{i 1}(y)-\xi_{i 0}\right)
\end{array}\right) .
\end{aligned}
$$

The equilibrium portfolios and the equilibrium prices are the implicit solutions of the system of equations which arise from the first-order conditions for the portfolio of each asset,

$$
\begin{gathered}
\frac{\partial \overline{\mathcal{L}}_{i}}{\partial x_{i 1}}=m_{i 1}-r \sigma_{i 1}^{2} x_{i 1}(y)+\frac{\partial g_{i}\left(x_{i 1}(y), \theta_{i 1}(y), \xi_{i 1}(y)\right)}{\partial x_{i 1}}-p_{1}(y)=0, \\
\frac{\partial \overline{\mathcal{L}}_{i}}{\partial \theta_{i 1}}=\frac{\partial g_{i}\left(x_{i 1}(y), \theta_{i 1}(y), \xi_{i 1}(y)\right)}{\partial \theta_{i 1}}-\pi_{1}(y)=0, \\
\frac{\partial \overline{\mathcal{L}}_{i}}{\partial \xi_{i 1}}=\frac{\partial g_{i}\left(x_{i 1}(y), \theta_{i 1}(y), \xi_{i 1}(y)\right)}{\partial \xi_{i 1}}-v_{1}(y)=0,
\end{gathered}
$$

and the market clearing condition for each asset, i.e.,

$$
\sum_{i=1}^{I} \xi_{i 1}(y)=0, \quad \sum_{i=1}^{I} \theta_{i 1}(y)=0, \text { and } \sum_{i=1}^{I} x_{i 1}(y)=Z .
$$

\section{B.2.2 Equilibrium Prices at $t=0$}

I now determine the equilibrium prices and the equilibrium demands at $t=0$, taking the

equilibrium at $t=1$ characterized by the system of equations, i.e., Eq. (B1) to Eq. (B4) as given. From the perspective of $t=0$, the date $t=2$ consumption for the investor $i$ is

$$
\begin{aligned}
c_{i 2}= & \xi_{i 1}(y)\left(\max (K-d, 0)-v_{1}(y)\right)+\xi_{i 0} v_{1}(y) \\
& +\theta_{i 1}(y)\left(\max (d-K, 0)-\pi_{1}(y)\right)+\theta_{i 0} \pi_{1}(y) \\
& +x_{i 1}(y)\left(d-p_{1}(y)\right)+x_{i 0} p_{1}(y)+\gamma_{i 0} \\
= & \xi_{i 1}(y) \max (K-d, 0)+\theta_{i 1}(y) \max (d-K, 0)+x_{i 1}(y) d \\
& +\left(\xi_{i 0}-\xi_{i 1}(y)\right) v_{1}(y)+\left(\theta_{i 0}-\theta_{i 1}(y)\right) \pi_{1}(y) \\
& +\left(x_{i 0}-x_{i 1}(y)\right) p_{1}(y)+\gamma_{i 0} .
\end{aligned}
$$

By Lemma 2, conditional on the information at $t=1$, the investor $i$ 's certainty equivalent 
of $t=2$ consumption is

$$
\begin{aligned}
& \mathrm{CE}_{i 2}\left(\bar{z}_{i}, x_{i 0}, \theta_{i 0}, x_{i 1}(y), \theta_{i 1}(y), p_{0}(\eta), p_{1}(y), \pi_{0}(\eta), \pi_{1}(y), \gamma_{i 0} \mid \mathcal{F}_{1}\right) \\
= & \left(\xi_{i 0}-\xi_{i 1}(y)\right) v_{1}(y)+\left(\theta_{i 0}-\theta_{i 1}(y)\right) \pi_{1}(y) \\
& +\left(x_{i 0}-x_{i 1}(y)\right) p_{1}(y)+\gamma_{i 0}+m_{i 1} x_{i 1}(y)-\frac{1}{2} r \sigma_{i 1}^{2} x_{i 1}^{2}(y) \\
& -\frac{1}{r} \ln \left\{\exp \left[-r \xi_{i 1}(y)\left[K-m_{i 1}-\frac{1}{2} r \sigma_{i 1}^{2} \xi_{i 1}(y)+r \sigma_{i 1}^{2} x_{i 1}(y)\right]\right]\right. \\
& \times \Phi\left(\frac{K-\left(m_{i 1}-r \sigma_{i 1}^{2}\left(x_{i 1}(y)-\xi_{i 1}(y)\right)\right)}{\sigma_{i 1}}\right) \\
& +\exp \left[-r \theta_{i 1}(y)\left[-K+m_{i 1}-\frac{1}{2} r \sigma_{i 1}^{2} \theta_{i 1}(y)-r \sigma_{i 1}^{2} x_{i 1}(y)\right]\right] \\
& \left.\times\left(1-\Phi\left(\frac{K-\left(m_{i 1}-r \sigma_{i 1}^{2}\left(\theta_{i 1}(y)+x_{i 1}(y)\right)\right)}{\sigma_{i 1}}\right)\right)\right\},
\end{aligned}
$$

where $\mathcal{F}_{1}$ denotes the investors' public information at date $t=1$.

Conditional on the information at $t=1$, the investor $i$ 's certainty equivalent of $t=2$ consumption varies with the investors' posterior beliefs $m_{i 1}$ and $\sigma_{i 1}^{2}$, and thus is a function of the public signal $y$. Note from the perspective of the investor $i, y \sim N\left(m_{i}, \sigma_{i}^{2}+\sigma_{\varepsilon}^{2}\right)$.

Moreover, the investor $i$ 's $t=0$ certainty equivalent equals to the date $t=0$ consumption, i.e.,

$$
\mathrm{CE}_{i 0}=c_{i 0}=d_{0} \bar{z}_{i}+\left(\bar{\xi}_{i}-\xi_{i 0}\right) v_{0}(\eta)+\left(\bar{\theta}_{i}-\theta_{i 0}\right) \pi_{0}(\eta)+\left(\bar{\gamma}_{i}-\gamma_{i 0}\right) \beta_{0}+\left(\bar{z}_{i}-x_{i 0}\right) p_{0}(\eta),
$$

hence the investor $i$ 's decision problem at $t=0$ can be stated as follows

$$
\max _{\xi_{i 0}, \theta_{i 0}, \gamma_{i 0}, x_{i 0}}-\exp \left(-r \mathrm{CE}_{i 0}\right)-\exp (-\delta) \exp \left(-r \mathrm{CE}_{i 2}\right)
$$

Solve the investor $i$ 's optimal portfolio choice problem, the equilibrium portfolios and the prices are the implicit solutions of the system of equations which arise from the first-order conditions for the portfolio of each asset, i.e., 


$$
\begin{aligned}
& \frac{\partial\left(-\exp \left(-r \mathrm{CE}_{i 0}\right)-\exp (-\delta) \exp \left(-r \mathrm{CE}_{i 2}\right)\right)}{\partial \xi_{i 0}}=0, \\
& \frac{\partial\left(-\exp \left(-r \mathrm{CE}_{i 0}\right)-\exp (-\delta) \exp \left(-r \mathrm{CE}_{i 2}\right)\right)}{\partial x_{i 0}}=0, \\
& \frac{\partial\left(-\exp \left(-r \mathrm{CE}_{i 0}\right)-\exp (-\delta) \exp \left(-r \mathrm{CE}_{i 2}\right)\right)}{\partial \theta_{i 0}}=0, \\
& \frac{\partial\left(-\exp \left(-r \mathrm{CE}_{i 0}\right)-\exp (-\delta) \exp \left(-r \mathrm{CE}_{i 2}\right)\right)}{\partial \gamma_{i 0}}=0,
\end{aligned}
$$

and the market clearing condition for each asset, i.e.,

$$
\sum_{i=1}^{I} \gamma_{i 0}=0, \quad \sum_{i=1}^{I} \xi_{i 0}=0, \quad \sum_{i=1}^{I} \theta_{i 0}=0, \text { and } \sum_{i=1}^{I} x_{i 0}=Z
$$

\section{B.3 Proof of Lemma 2}

Since the investor $i$ 's consumption at $t=2$

$$
c_{i 2}=\theta_{i 0} \max (d-K, 0)+\xi_{i 0} \max (K-d, 0)+x_{i 0} d+\gamma_{i 0},
$$

hence the $t=2$ expected utility for the investor $i$ is

$$
\begin{aligned}
-\mathrm{E}\left[\exp \left[-r\left[\theta_{i 0} \max (d-K, 0)+\xi_{i 0} \max (K-d, 0)+x_{i 0} d+\gamma_{i 0}\right]\right]\right] \\
=-\int_{-\infty}^{+\infty} \exp \left[-r\left[\theta_{i 0} \max (d-K, 0)+\xi_{i 0} \max (K-d, 0)+x_{i 0} d+\gamma_{i 0}\right]\right] f\left(x ; m_{i 0}, \sigma_{i 0}^{2}\right) d x \\
=-\int_{-\infty}^{K} \exp \left[-r\left[\left(x_{i 0}-\xi_{i 0}\right) d+\xi_{i 0} K+\gamma_{i 0}\right]\right] f\left(x ; m_{i 0}, \sigma_{i 0}^{2}\right) d x \\
-\int_{K}^{+\infty} \exp \left[-r\left[\left(\theta_{i 0}+x_{i 0}\right) d-\theta_{i 0} K+\gamma_{i 0}\right]\right] f\left(x ; m_{i 0}, \sigma_{i 0}^{2}\right) d x \\
=-\exp \left[-r\left[\gamma_{i 0}+\xi_{i 0} K+m_{i 0}\left(x_{i 0}-\xi_{i 0}\right)-\frac{1}{2} r \sigma_{i 0}^{2}\left(x_{i 0}-\xi_{i 0}\right)^{2}\right]\right] \\
\quad \times \int_{-\infty}^{K} f\left(x ; m_{i 0}-r \sigma_{i 0}^{2}\left(x_{i 0}-\xi_{i 0}\right), \sigma_{i 0}^{2}\right) d x \\
\quad-\exp \left[-r\left[\gamma_{i 0}-\theta_{i 0} K+m_{i 0}\left(\theta_{i 0}+x_{i 0}\right)-\frac{1}{2} r \sigma_{i 0}^{2}\left(\theta_{i 0}+x_{i 0}\right)^{2}\right]\right] \\
\quad \times \int_{K}^{+\infty} f\left(x ; m_{i 0}-r \sigma_{i 0}^{2}\left(\theta_{i 0}+x_{i 0}\right), \sigma_{i 0}^{2}\right) d x
\end{aligned}
$$




$$
\begin{aligned}
& =-\exp \left[-r\left[\gamma_{i 0}+\xi_{i 0} K+m_{i 0}\left(x_{i 0}-\xi_{i 0}\right)-\frac{1}{2} r \sigma_{i 0}^{2}\left(x_{i 0}-\xi_{i 0}\right)^{2}\right]\right] \\
& \times \int_{-\infty}^{\frac{K-\left(m_{i 0}-r \sigma_{i 0}^{2}\left(x_{i 0}-\xi_{i 0}\right)\right)}{\sigma_{i 0}}} \phi(x) d x \\
& -\exp \left[-r\left[\gamma_{i 0}-\theta_{i 0} K+m_{i 0}\left(\theta_{i 0}+x_{i 0}\right)-\frac{1}{2} r \sigma_{i 0}^{2}\left(\theta_{i 0}+x_{i 0}\right)^{2}\right]\right] \\
& \times \int_{\frac{K-\left(m_{i 0}-r \sigma_{i 0}^{2}\left(\theta_{i 0}+x_{i 0}\right)\right)}{\sigma_{i 0}}}^{+\infty} \phi(x) d x \\
& =-\exp \left[-r\left[\gamma_{i 0}+\xi_{i 0} K+m_{i 0}\left(x_{i 0}-\xi_{i 0}\right)-\frac{1}{2} r \sigma_{i 0}^{2}\left(x_{i 0}-\xi_{i 0}\right)^{2}\right]\right] \\
& \times \Phi\left(\frac{K-\left(m_{i 0}-r \sigma_{i 0}^{2}\left(x_{i 0}-\xi_{i 0}\right)\right)}{\sigma_{i 0}}\right) \\
& -\exp \left[-r\left[\gamma_{i 0}-\theta_{i 0} K+m_{i 0}\left(\theta_{i 0}+x_{i 0}\right)-\frac{1}{2} r \sigma_{i 0}^{2}\left(\theta_{i 0}+x_{i 0}\right)^{2}\right]\right] \\
& \times\left(1-\Phi\left(\frac{K-\left(m_{i 0}-r \sigma_{i 0}^{2}\left(\theta_{i 0}+x_{i 0}\right)\right)}{\sigma_{i 0}}\right)\right) \\
& =-\exp \left[-r\left[\begin{array}{c}
\gamma_{i 0}+m_{i 0} x_{i 0}-\frac{1}{2} r \sigma_{i 0}^{2} x_{i 0}^{2}+\xi_{i 0} K-m_{i 0} \xi_{i 0} \\
-\frac{1}{2} r \sigma_{i 0}^{2} \xi_{i 0}^{2}+r \sigma_{i 0}^{2} x_{i 0} \xi_{i 0}
\end{array}\right]\right] \\
& \times \Phi\left(\frac{K-\left(m_{i 0}-r \sigma_{i 0}^{2}\left(x_{i 0}-\xi_{i 0}\right)\right)}{\sigma_{i 0}}\right) \\
& -\exp \left[-r\left[\begin{array}{c}
\gamma_{i 0}+m_{i 0} x_{i 0}-\frac{1}{2} r \sigma_{i 0}^{2} x_{i 0}^{2}-\theta_{i 0} K+m_{i 0} \theta_{i 0} \\
-\frac{1}{2} r \sigma_{i 0}^{2} \theta_{i 0}^{2}-r \sigma_{i 0}^{2} \theta_{i 0} x_{i 0}
\end{array}\right]\right] \\
& \times\left(1-\Phi\left(\frac{K-\left(m_{i 0}-r \sigma_{i 0}^{2}\left(\theta_{i 0}+x_{i 0}\right)\right)}{\sigma_{i 0}}\right)\right)
\end{aligned}
$$




$$
\begin{aligned}
= & -\exp \left[-r\left[\gamma_{i 0}+m_{i 0} x_{i 0}-\frac{1}{2} r \sigma_{i 0}^{2} x_{i 0}^{2}\right]\right] \\
& \left\{\exp \left[-r\left[\xi_{i 0} K-m_{i 0} \xi_{i 0}-\frac{1}{2} r \sigma_{i 0}^{2} \xi_{i 0}^{2}+r \sigma_{i 0}^{2} x_{i 0} \xi_{i 0}\right]\right]\right. \\
& \times \Phi\left(\frac{K-\left(m_{i 0}-r \sigma_{i 0}^{2}\left(x_{i 0}-\xi_{i 0}\right)\right)}{\sigma_{i 0}}\right) \\
& +\exp \left[-r\left[-\theta_{i 0} K+m_{i 0} \theta_{i 0}-\frac{1}{2} r \sigma_{i 0}^{2} \theta_{i 0}^{2}-r \sigma_{i 0}^{2} \theta_{i 0} x_{i 0}\right]\right] \\
& \left.\times\left(1-\Phi\left(\frac{K-\left(m_{i 0}-r \sigma_{i 0}^{2}\left(\theta_{i 0}+x_{i 0}\right)\right)}{\sigma_{i 0}}\right)\right)\right\}
\end{aligned}
$$

Therefore, the certainty equivalent of $t=2$ consumption for the investor $i$ is

$$
\begin{aligned}
\mathrm{CE}_{i 2}= & -\frac{1}{r} \ln \left(-U_{i 2}\left(\theta_{i 0}, x_{i 0}, \gamma_{i 0} \mid m_{i 0}, \sigma_{i 0}^{2}\right)\right) \\
= & \gamma_{i 0}+m_{i 0} x_{i 0}-\frac{1}{2} r \sigma_{i 0}^{2} x_{i 0}^{2} \\
& -\frac{1}{r} \ln \left\{\exp \left[-r \xi_{i 0}\left[K-m_{i 0}-\frac{1}{2} r \sigma_{i 0}^{2} \xi_{i 0}+r \sigma_{i 0}^{2} x_{i 0}\right]\right]\right. \\
& \times \Phi\left(\frac{K-\left(m_{i 0}-r \sigma_{i 0}^{2}\left(x_{i 0}-\xi_{i 0}\right)\right)}{\sigma_{i 0}}\right) \\
& +\exp \left[-r \theta_{i 0}\left[-K+m_{i 0}-\frac{1}{2} r \sigma_{i 0}^{2} \theta_{i 0}-r \sigma_{i 0}^{2} x_{i 0}\right]\right] \\
& \left.\times\left(1-\Phi\left(\frac{K-\left(m_{i 0}-r \sigma_{i 0}^{2}\left(\theta_{i 0}+x_{i 0}\right)\right)}{\sigma_{i 0}}\right)\right)\right\} .
\end{aligned}
$$

This completes the proof. 


\section{B.4 Calculate the First Derivatives in Model B.1 and B.2}

This section provides the calculation of the first derivatives in the first-order condition in model B.1 and B.2. Let

$$
\begin{aligned}
\bar{a}_{i} & =\frac{K-\left(m_{i 0}-r \sigma_{i 0}^{2}\left(x_{i 0}-\xi_{i 0}\right)\right)}{\sigma_{i 0}}, \\
\bar{b}_{i} & =\frac{K-\left(m_{i 0}-r \sigma_{i 0}^{2}\left(\theta_{i 0}+x_{i 0}\right)\right)}{\sigma_{i 0}}, \\
\bar{c}_{i} & =\exp \left[-r \theta_{i 0}\left[-K+m_{i 0}-\frac{1}{2} r \sigma_{i 0}^{2} \theta_{i 0}-r \sigma_{i 0}^{2} x_{i 0}\right]\right], \\
\bar{d}_{i} & =\exp \left[-r \xi_{i 0}\left[K-m_{i 0}-\frac{1}{2} r \sigma_{i 0}^{2} \xi_{i 0}+r \sigma_{i 0}^{2} x_{i 0}\right]\right]
\end{aligned}
$$

therefore,

$$
g_{i}\left(x_{i 0}, \theta_{i 0}, \xi_{i 0}\right)=-\frac{1}{r} \ln \left\{\bar{d}_{i} \times \Phi\left(\bar{a}_{i}\right)+\bar{c}_{i} \times\left(1-\Phi\left(\bar{b}_{i}\right)\right)\right\},
$$

and $\Phi(\cdot)$ is the cumulative distribution function of the standard normal distribution. Hence

$$
\begin{gathered}
\bar{d}_{i} \phi\left(\bar{a}_{i}\right) \sigma_{i 0}-\bar{d}_{i} \Phi\left(\bar{a}_{i}\right) r \sigma_{i 0}^{2} \xi_{i 0} \\
\frac{\partial g_{i}\left(x_{i 0}, \theta_{i 0}, \xi_{i 0}\right)}{\partial x_{i 0}}=-\frac{-\phi\left(\bar{b}_{i}\right) \sigma_{i 0} \bar{c}_{i}+\left(1-\Phi\left(\bar{b}_{i}\right)\right) \bar{c}_{i} r \sigma_{i 0}^{2} \theta_{i 0}}{\bar{d}_{i} \Phi\left(\bar{a}_{i}\right)+\left(1-\Phi\left(\bar{b}_{i}\right)\right) \bar{c}_{i}} \\
\frac{\partial g_{i}\left(x_{i 0}, \theta_{i 0}, \xi_{i 0}\right)}{\partial \theta_{i 0}}=\frac{\phi\left(\bar{b}_{i}\right) \sigma_{i 0} \bar{c}_{i}+\left(1-\Phi\left(\bar{b}_{i}\right)\right)\left(m_{i 0}-K-r \sigma_{i 0}^{2} \theta_{i 0}-r \sigma_{i 0}^{2} x_{i 0}\right) \bar{c}_{i}}{\bar{d}_{i} \Phi\left(\bar{a}_{i}\right)+\left(1-\Phi\left(\bar{b}_{i}\right)\right) \bar{c}_{i}} \\
\frac{\partial g_{i}\left(x_{i 0}, \theta_{i 0}, \xi_{i 0}\right)}{\partial \xi_{i 0}}=\frac{\phi\left(\bar{a}_{i}\right) \sigma_{i 0} \bar{d}_{i}+\Phi\left(\bar{a}_{i}\right)\left(K-m_{i 0}-r \sigma_{i 0}^{2} \xi_{i 0}+r \sigma_{i 0}^{2} x_{i 0}\right) \bar{d}_{i}}{\bar{d}_{i} \Phi\left(\bar{a}_{i}\right)+\left(1-\Phi\left(\bar{b}_{i}\right)\right) \bar{c}_{i}},
\end{gathered}
$$

where $\phi(x)$ denotes the standard normal probability density function, hence

$$
\phi(x)=\frac{1}{\sqrt{2 \pi}} \exp \left(-\frac{x^{2}}{2}\right)
$$


2012-06: $\quad$ Christian Bach and Matt P. Dziubinski: Commodity derivatives pricing with inventory effects

2012-07: Cristina Amado and Timo Teräsvirta: Modelling Changes in the Unconditional Variance of Long Stock Return Series

2012-08: $\quad$ Anne Opschoor, Michel van der Wel, Dick van Dijk and Nick Taylor: On the Effects of Private Information on Volatility

2012-09: Annastiina Silvennoinen and Timo Teräsvirta: Modelling conditional correlations of asset returns: A smooth transition approach

2012-10: $\quad$ Peter Exterkate: Model Selection in Kernel Ridge Regression

2012-11: $\quad$ Torben G. Andersen, Nicola Fusari and Viktor Todorov: Parametric Inference and Dynamic State Recovery from Option Panels

2012-12: $\quad$ Mark Podolskij and Katrin Wasmuth: Goodness-of-fit testing for fractional diffusions

2012-13: $\quad$ Almut E. D. Veraart and Luitgard A. M. Veraart: Modelling electricity day-ahead prices by multivariate Lévy

2012-14: $\quad$ Niels Haldrup, Robinson Kruse, Timo Teräsvirta and Rasmus T. Varneskov: Unit roots, nonlinearities and structural breaks

2012-15: $\quad$ Matt P. Dziubinski and Stefano Grassi: Heterogeneous Computing in Economics: A Simplified Approach

2012-16: $\quad$ Anders Bredahl Kock and Laurent A.F. Callot: Oracle Inequalities for High Dimensional Vector Autoregressions

2012-17: $\quad$ Eric Hillebrand, Huiyu Huang, Tae-Hwy Lee and Canlin Li: Using the Yield Curve in Forecasting Output Growth and Inflation

2012-18: $\quad$ Eric Hillebrand and Tae-Hwy Lee: Stein-Rule Estimation and Generalized Shrinkage Methods for Forecasting Using Many Predictors

2012-19: Bent J esper Christensen, Morten Ørregaard Nielsen and J ie Zhu: The impact of financial crises on the risk-return tradeoff and the leverage effect

2012-20: Hendrik Kaufmann, Robinson Kruse and Philipp Sibbertsen: On tests for linearity against STAR models with deterministic trends

2012-21: $\quad$ Andrey Launov, Olaf Posch and Klaus Wälde: On the estimation of the volatility-growth link

2012-22: $\quad$ Peter O. Christensen and Zhenjiang Qin: Information and Heterogeneous Beliefs: Cost of Capital, Trading Volume, and Investor Welfare

2012-23: $\quad$ Zhenjiang Qin: Heterogeneous Beliefs, Public Information, and Option Markets 